\title{
Potential Impacts of Accelerated Climate Change
}

\section{Annual Report of Work for NRC Agreement Number NRC-HQ-60-14-D-0025}

\section{May 2016}

LR Leung

LW Vail 


\title{
DISCLAIMER
}

This report was prepared as an account of work sponsored by an agency of the United States Government. Neither the United States Government nor any agency thereof, nor Battelle Memorial Institute, nor any of their employees, makes any warranty, express or implied, or assumes any legal liability or responsibility for the accuracy, completeness, or usefulness of any information, apparatus, product, or process disclosed, or represents that its use would not infringe privately owned rights. Reference herein to any specific commercial product, process, or service by trade name, trademark, manufacturer, or otherwise does not necessarily constitute or imply its endorsement, recommendation, or favoring by the United States Government or any agency thereof, or Battelle Memorial Institute. The views and opinions of authors expressed herein do not necessarily state or reflect those of the United States Government or any agency thereof.

\author{
PACIFIC NORTHWEST NATIONAL LABORATORY \\ operated by \\ BATTELLE \\ for the \\ UNITED STATES DEPARTMENT OF ENERGY \\ under Contract DE-AC05-76RL01830
}

Printed in the United States of America
Available to DOE and DOE contractors from the Office of Scientific and Technical Information,
P.O. Box 62, Oak Ridge, TN 37831-0062; ph: (865) 576-8401
fax: $(865) 576-5728$
email: reports(a)adonis.osti.gov

Available to the public from the National Technical Information Service 5301 Shawnee Rd., Alexandria, VA 22312

ph: (800) 553-NTIS (6847)

email: orders@ntis.gov $<$ http://www.ntis.gov/about/form.aspx $>$

Online ordering: http://www.ntis.gov

This document was printed on recycled paper. 


\section{Potential Impacts of Accelerated Climate Change}

Annual Report of Work for NRC Agreement Number

NRC-HQ-60-14-D-0025

May 2016

LR Leung

LW Vail

Prepared for the U.S. Nuclear Regulatory Commission under an Interagency Agreement with the U.S. Department of Energy Contract DE-AC05-76RL01830

Pacific Northwest National Laboratory

Richland, Washington 99352 



\begin{abstract}
This research project is part of the U.S. Nuclear Regulatory Commission's (NRC's) Probabilistic Flood Hazard Assessment (PFHA) research plan in support of developing a risk-informed licensing framework for flood hazards and design standards at proposed new facilities and significance determination tools for evaluating potential deficiencies related to flood protection at operating facilities. The PFHA plan aims to build upon recent advances in deterministic, probabilistic, and statistical modeling of extreme precipitation events to develop regulatory tools and guidance for NRC staff with regard to PFHA for nuclear facilities. The tools and guidance developed under the PFHA plan will support and enhance the NRC's capacity to perform thorough and efficient reviews of license applications and license amendment requests. They will also support risk-informed significance determination of inspection findings, unusual events, and other oversight activities.

For Year 1, specifically, Pacific Northwest National Laboratory (PNNL) staff:

- prepared an annual report that summarizes recent scientific findings, reports on activities of federal agencies with direct responsibility for climate change science, and provide a qualitative assessment of these findings relevant to NRC concerns on a regional level (i.e., increasing air and water temperatures, decreasing water availability, increasing frequency and intensity of storms and flooding, and sea level rise)

- participated in annual webinars with NRC staff at NRC Headquarters in Rockville, Maryland

- presented updates summarizing recent scientific findings at the NRC PFHA Workshop Headquarters in Rockville, Maryland.
\end{abstract}

PNNL staff have identified neither technical nor programmatic issues in proceeding with Year 2 activities. 



\section{Executive Summary}

This report summarizes Pacific Northwest National Laboratory (PNNL) staff efforts over the first year of the U.S. Nuclear Regulatory Commission's (NRC's) Probabilistic Flood Hazard Assessment (PFHA) research project. The NRC's safety reviews and environmental reviews are fundamentally different processes and have substantially different needs. The NRC's environmental reviews directly reference climate research published in the U.S. Global Change Research Program (USGCRP) National Assessment. From the NRC safety perspective, climate research is unlikely to provide direct information at annual exceedance probability level of 0.001 or less in the near future. However, an improved understanding of large-scale climate pattern changes (e.g., the occurrence of extreme precipitation events such atmospheric rivers, rain, on snow with frozen soil) can help inform the probabilistic characterization (i.e., likelihood) of extreme events. Hence, this report includes a literature review, focusing on recent studies that improve understanding of the mechanisms of how the climate parameters relevant to the NRC may change in a warmer climate, including discussions of the robust and uncertain aspects of the changes and future directions for reducing uncertainty in projecting those changes. The literature review is followed by a summary of key findings from two recent reports that synthesize analysis of the historical climate changes from the observational records and projected regional climate changes from ensembles of regional and global climate models for the United States. Lastly, a current assessment of climate modeling and federal agency activities related to climate change is presented.

Overall, surface temperature is projected to increase as greenhouse gas emissions continue in the future. This is accompanied by increases in heat wave intensity and frequency and reductions in cold extremes. As the atmospheric water vapor holding capacity increases with temperature, global precipitation is expected to increase, with regional differences. Extreme precipitation is projected to increase more than the mean precipitation, and extreme snowfall is expected to increase, despite a general reduction of mean snowfall in a warmer climate. In the western United States, atmospheric rivers, which are the dominant flood producers, are projected to increase in frequency by 50 to 600 percent due primarily to the increase in atmospheric moisture. In regions where heavy precipitation originates primarily from summer convective storms (e.g., the Great Plains), observation data suggest a 7 percent increase in convective extreme precipitation per degree of warming. At the same time, aridity will generally increase due to the increasing saturation deficit over land, with robust drought risks projected for the southwestern and central United States. Increases in ocean heat content in a warmer climate will generally increase hurricane intensity, but climate models do not project robust Atlantic tropical cyclone frequency changes. In a warmer and moister atmosphere under global warming, hazardous convective weather that generates strong, damaging winds is generally projected to increase, though a reduction in wind shear due to polar amplification may offset some of the changes. Projections of sea level rise in the $21^{\text {st }}$ century show the largest increase in the Gulf Coast, followed by the eastern United States, where uncertainty is the largest. Selected regional climate changes are highlighted in the table below for each conterminous U.S. region.

By providing a high-level review of recent advances in climate change science and synopsis of regional climate change in the United States from recent assessments, this first annual report letter aims to build the foundation for a more comprehensive review of understanding and assessment of climate changes relevant to NRC needs over three years of the project. 


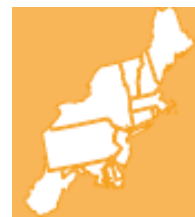

Northeast

- largest increase in very heavy precipitation historically among all U.S. regions

- more extreme rainfall and snowfall, influenced by storm surge and sea level rise (i.e., $0.75-1 \mathrm{~m}$ by the end of the $21^{\text {st }}$ century)

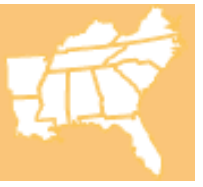

Southeast

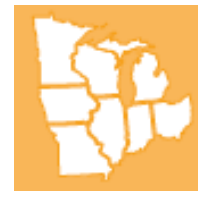

Midwest

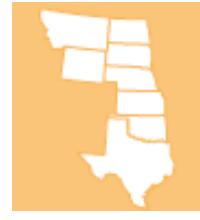

Great Plains

- increased risks of more intense hurricanes

- sea level rise in the 21 st century projected to be larger than $1 \mathrm{~m}$

- sea level rise and increased hurricane risks increase vulnerability to storm surge and coastal inundation

- increased occurrence of heat waves and droughts

- more intense convective extreme precipitation

- increased flood risks

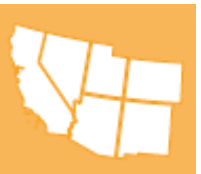

Southwest

- robust increased drought risks

- increased frequency of atmospheric rivers and associated heavy precipitation

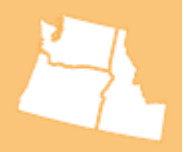

Northwest

- increased frequency of atmospheric rivers and associated heavy precipitation

- changes in streamflow timing due to warming-induced early snowmelt

\section{- robust increased drought risks}

- higher likelihood of hazardous convective weather

- sea level rise in the Gulf Coast 


\section{Glossary}

Atmospheric rivers: Atmospheric rivers are narrow filaments of enhanced atmospheric water vapor extending from the tropics to the mid-latitudes. Commonly known as 'pineapple express,' they are responsible for over 90 percent of the poleward moisture transport in the atmosphere, although on average only 4 to 5 atmospheric rivers occupying less than 10 percent of the zonal circumference are present at any time. Upon landfall, atmospheric rivers often produce heavy precipitation because of the large moisture flux convergence produced as they encounter mountains (e.g., the coastal ranges and the cordillera of western North and South America and the mountains in Western Europe).

Blocking: When large-scale atmospheric circulation patterns are nearly stationary, migratory extratropical cyclones or synoptic disturbances can be 'blocked' or redirected by the stationary highpressure fields, leading to an extended period of clear or stormy weather in different regions influenced by the circulation patterns. In the northern hemisphere, blocking occurs most frequently over the North Pacific and northeastern Atlantic Oceans during the cold season. Cold air outbreaks can develop on the eastern side of blocking anticyclones that direct Arctic air mass to the mid-latitudes.

Clausius-Clapeyron relation: The Clausius-Clapeyron relation characterizes the discontinuous phase transition between two phases of a single constituent. The Clausius-Clapeyron equation for atmospheric water vapor is given by:

$$
\frac{\mathrm{d} e_{s}}{\mathrm{~d} T}=\frac{L_{v}(T) e_{s}}{R_{v} T^{2}}
$$

where $e_{s}$ is saturation vapor pressure, $T$ is temperature, $L_{v}$ is the specific latent heat of vaporization, and $R_{v}$ is the gas constant of water vapor. In typical atmospheric conditions, the above equation can be approximated by

$$
e_{s}(T)=6.1094 \exp \left(\frac{17.625 T}{T+243.04}\right)
$$

Hence $e_{s}$ changes approximately exponentially with temperature, so the water-holding capacity of the atmosphere increases by about 7 percent per degree $\mathrm{K}$ of temperature rise. In climate simulations, global mean precipitable water (i.e., vertically integrated water vapor) increases with global mean surface temperature at a rate of $\sim 7.5 \%$ per degree $\mathrm{K}$ of warming.

CMIP5: The Coupled Model Intercomparison Project (CMIP) is a framework for coordinated climate change experiments. The fifth phase of CMIP (CMIP5) provided simulations for the Intergovernmental Panel of Climate Change (IPCC) Fifth Assessment Report (AR5). Modeling centers that participated in CMIP5 performed climate simulations following a common experimental protocol and archived their model outputs using a common data format to facilitate access and analysis of the multi-model ensemble for improving understanding of the drivers of climate change, projecting future climate change, and characterizing uncertainties due to model and scenario differences.

Hazardous convective weather: Hazardous convective weather (HCW) is produced by severe convection that generates tornadoes, hail, and damaging winds. HCW can cause damage to property and loss of life. Three ingredients are essential to support HCW: vertical wind shear contributes to the organization and longevity of severe convection, thermodynamics that support development of updraft, and an initiation process for convection. Hence the seasonality of $\mathrm{HCW}$ favorable environments correlates quite well with the seasonality of $\mathrm{HCW}$ occurrence. 
Mesoscale convective systems: Mesoscale convective systems (MCSs) are the largest convective clouds that can be identified by satellite infrared imagery of a large, contiguous precipitation area $\sim 100 \mathrm{~km}$ or more in at least one direction. The MCS rain area can be divided into convective and stratiform regions. MCSs are often found downwind of mountain ranges, so they occur frequently in spring and summer in the Great Plains when deep convection initiated in the Rocky Mountain in the late afternoon propagates eastward. With moisture supplied by the southerly flow from the Gulf of Mexico, the convective cells organize into large MCSs that produce nocturnal precipitation in the Great Plains. MCSs are responsible for $\sim 60$ percent of summer rainfall in the Great Plains.

RCP: Representative Concentration Pathways (RCPs) are four trajectories of greenhouse gas concentration used in IPCC AR5 for projection of future climate by global climate models (see the figure that follows). The RCPs are developed by integrated assessment models (MESSAGE, AIM, MiniCAM, and IMAGE) that consider the interactions among climate, energy economics, land cover and land use, and socio-economics to limit the radiative forcing in 2100 to $2.6,4.5,6.0$ and $8.5 \mathrm{Wm}^{-2}$ relative to the pre-industrial values. RCP8.5 is commonly known as the 'business-as-usual' scenario, while RCP2.6, RCP4.5, and RCP6 represent different mitigation scenarios to curb the radiative forcing.

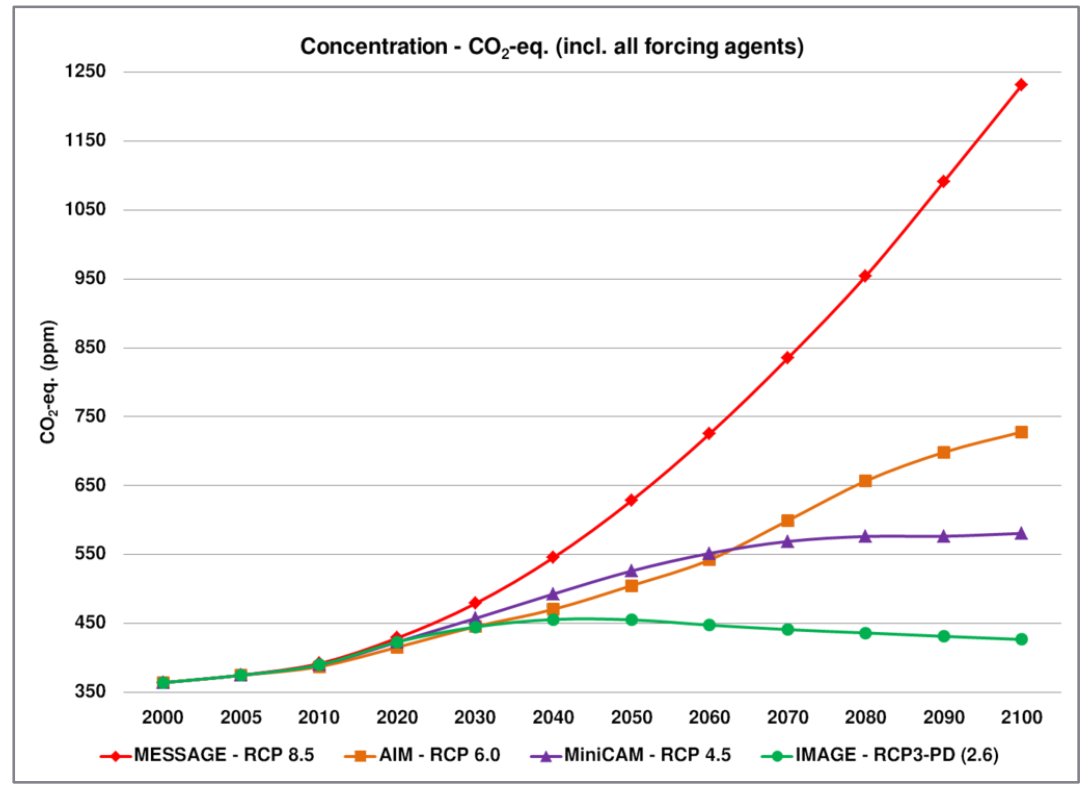




\section{Acronyms and Abbreviations}

AR

CAO

CAPE

$\mathrm{CC}$

CMIP

DOE

ETCCDI

$\mathrm{HCW}$

IPCC

IT

MCS

NARCCAP

NASA

NOAA

NRC

PDF

PFHA

PI

PNNL

$\mathrm{RCP}$

TC

USGCRP atmospheric rivers

cold air outbreaks

convective available potential energy

Clausius-Clapeyron

Coupled Model Intercomparison Project

U.S. Department of Energy

Expert Team on Climate Change Detection and Indices

hazardous convective weather

Intergovernmental Panel of Climate Change

information technology

mesoscale convective systems

North American Regional Climate Change Assessment Program

National Aeronautics and Space Administration

National Oceanic and Atmospheric Administration

U.S. Nuclear Regulatory Commission

probability distribution functions

Probabilistic Flood Hazard Assessment

potential intensity

Pacific Northwest National Laboratory

representative concentration pathways

tropical cyclones

U.S. Global Change Research Program 



\section{Contents}

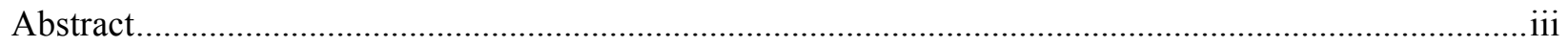

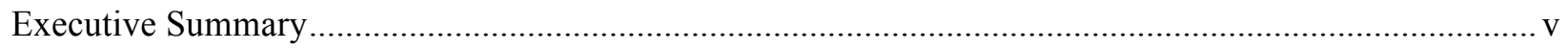

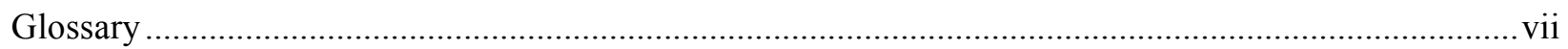

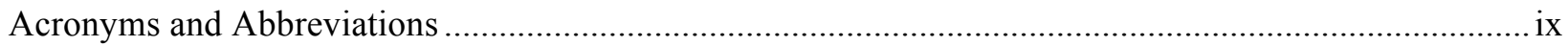

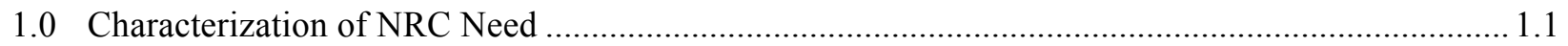

2.0 Recent Scientific Findings on Climate Change ...................................................................... 2.1

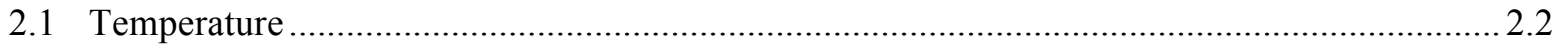

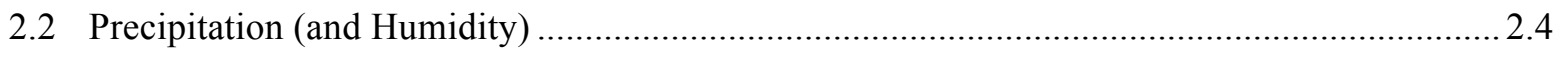

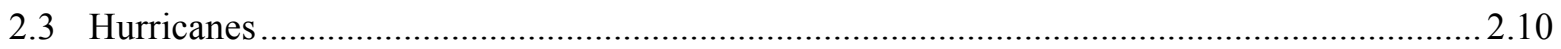

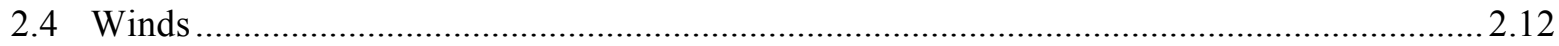

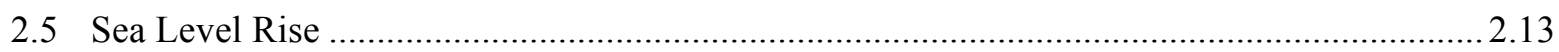

3.0 Summary of Climate Change Projections for the U.S. ................................................................. 2.1

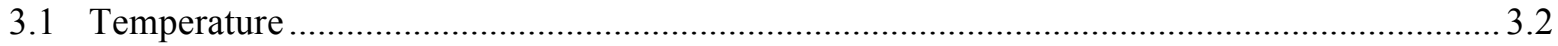

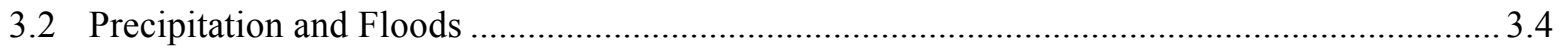

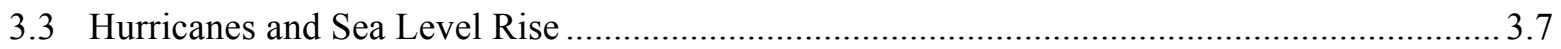

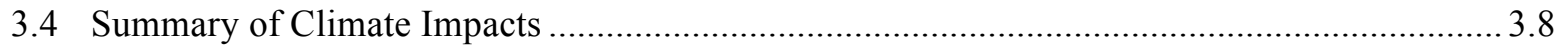

4.0 Status in Climate Modeling and Federal Agency Activities ....................................................... 4.1

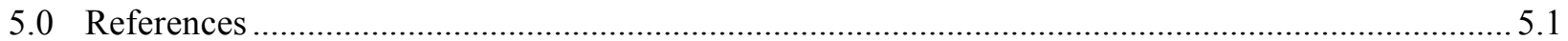




\section{Figures}

2.1 Regional climatic features in the conterminous U.S. relevant to the NRC's climate information needs

2.2 Changes in temperature of extreme hot days for winter and summer comparing 2080-2100 and 1985-2005 from the CMIP5 model projections following the RCP8.5 scenario.....

2.3 Changes in $99.9^{\text {th }}$ percentile daily extreme precipitation from CMIP5 models, showing a general increase of about 7 percent $\mathrm{K}^{-1}$ in the extratropics but larger uncertainty in the tropics

2.4 Number of AR days from CMIP5 simulations for the present, future, and for AR detected by scaling the future simulations with the present-day atmospheric moisture comparing the two decades near the end of the $21^{\text {st }}$ and $20^{\text {th }}$ centuries in the RCP8.5 scenario

2.5 Sensitivity of the $99^{\text {th }}$ percentile hourly precipitation per degree K of warming in the United States and the sensitivity for different percentile values for four U.S. sub-regions showing increasing sensitivity with increasing percentile values

2.6 The ratio of future to present mean snowfall and snowfall extremes showing much larger reduction from present to future for mean snowfall than snowfall extremes...

2.7 PDSI from North American Drought Atlas and CMIP5 models, and soil moisture at $30 \mathrm{~cm}$ and $2 \mathrm{~m}$ from CMIP5 models for the Central Plains and Southwest regions of North America

2.8 Poleward migration of the latitude of Lifetime-Maximum Intensity away from the tropics from the best-track historical data and the ADT-HURSAT reanalysis in the northern and southern hemispheres, and their annual mean difference. Observed changes from 1980-1994 to 1995-2010 in the mean vertical wind shear and potential intensity where TCs form and track

2.9 Changes in number of days with spring severe thunderstorm environment comparing 2070 to 2099 with 1970 to 1999 from CMIP5 models in the RCP8.5 scenario

2.10 Inter-model median and 17 to 83 percent range of sea level rise projected by a multi-model ensemble in meters

3.1 Temperature changes over the past 22 years compared to the 1901 to 1960 average, and compared to the 1951 to 1980 average for Alaska and Hawaii. The bars on the graphs show the average temperature changes by decade for 1901 to 2012 for each region

3.2 Projected changes in surface temperature from CMIP5 models using four emission scenarios corresponding to a climate forcing ranging from $2.6 \mathrm{Wm}^{-2}$ to $8.5 \mathrm{Wm}^{-2}$ by the end of the $21^{\text {st }}$ century

3.3 Same as Figure 3.2, but for changes in hottest and coldest days.....

3.4 Similar to Figure 3.1, but for observed precipitation changes

3.5 Projected changes in mean precipitation for four seasons from CMIP5 models using four emission scenarios corresponding to a climate forcing ranging from $2.6 \mathrm{Wm}^{-2}$ to $8.5 \mathrm{Wm}^{-2}$ by the end of the $21^{\text {st }}$ century

3.6 Similar to Figure 3.4 but for observed very heavy precipitation changes. Very heavy precipitation is defined as the heaviest 1 percent of all daily events from 1901 to 2012 for each region.

3.7 Percent increases in the amount of precipitation in very heavy events from 1958 to 2012 for each U.S. region 
3.8 Projected changes in the frequency of extreme precipitation events in two emission scenarios ....... 3.6

3.9 Trends of annual flood magnitude from 1920s through 2008 ......................................................... 3.6

3.10 Recent variations of the Power Dissipation Index in the North Atlantic and eastern North Pacific Oceans

3.11 Estimated, observed, and possible future amounts of global sea level rise from 1800 to 2100 relative to the year 2000

3.12 Summary of climate impacts by U.S. regions .......

\section{Tables}

1.1 Matrix of NRC's assessment topics and prioritized climate change information needs. 1.1

1.2 NRC and climate information needs related to local intense precipitation. 1.3 



\subsection{Characterization of NRC Need}

This research project is part of the U.S. Nuclear Regulatory Commission's (NRC's) Probabilistic Flood Hazard Assessment (PFHA) research plan in support of developing a risk-informed licensing framework for flood hazards and design standards at proposed new facilities and significance determination tools for evaluating potential deficiencies related to flood protection at operating facilities. The PFHA plan aims to build upon recent advances in deterministic, probabilistic, and statistical modeling of extreme precipitation events to develop regulatory tools and guidance for NRC staff with regard to PFHA for nuclear facilities. The tools and guidance developed under the PFHA plan will support and enhance the NRC's capacity to perform thorough and efficient reviews of license applications and license amendment requests. They will also support risk-informed significance determination of inspection findings, unusual events, and other oversight activities.

In order to focus the PNNL staff's consideration of processes and mechanisms that may be impacted by climate change, Mr. Lance Vail, a PNNL staff member with extensive experience in NRC safety and environmental reviews, developed a preliminary characterization of the nexus of NRC needs and climate change parameters, while Dr. L. Ruby Leung, a PNNL climate scientist, synthesized scientific understanding and findings on NRC-relevant climate change parameters in the United States. Mr. Vail's characterization is summarized in a matrix that represents his perspective and is considered an ongoing way of characterizing and focusing this project to align with NRC needs.

The matrix, shown below as Table 1.1, shows NRC's assessment topics for safety and environment reviews and prioritized climate change information needs for each review topic. The characterization as 'primary,' 'secondary,' and 'tertiary' needs does not imply that the other areas are of no interest, only that they are of lower priority. For instance, for Local Intense Precipitation, without substantial reduction in uncertainty of precipitation, any reduction of uncertainty in temperature would likely be of limited interest.

The NRC's safety reviews and environmental reviews are fundamentally different processes and have substantially different needs. Certain topics are only considered in one or the other. However, some topics (e.g., Local Intense Precipitation) are of interest to both reviews but have substantially different considerations. Mr. Vail documented his preliminary characterizations in a Microsoft Excel ${ }^{\mathrm{TM}}$ workbook. Separate sheets were used to elaborate on each topic. Table 1.2 is a current example of the sheet for Local Intense Precipitation.

The primary difference in environmental reviews and safety reviews is the degree of conservatism. Environmental reviews consider what is reasonably foreseeable over the license period (40 years of operation). So considering a 20 -year rainfall event for the design of a detention pond is reasonable. However, the time scales in safety reviews are vastly more onerous. Safety systems can be designed to be protected from events that may occur only once in 10,000 years. The uncertainty in 20-year estimates is far smaller than the uncertainty in a 10,000-year event. It is critical to keep in mind the difference in the definition of an 'extreme event' between an environmental review and a safety review.

Climate research published in the U.S. Global Change Research Program (USGCRP) National Assessment is directly referenced in NRC environmental reviews. The NRC's environmental review staff has developed an environmental impact statement appendix and associated spreadsheets that correlate NRC environmental assessment needs per Regulatory Guide 4.2 with USGCRP National Assessment findings. The appendix and spreadsheets are used to disclose NRC staff beliefs about the anticipated change in operational impacts over the license period from the current baseline affected environment to the reasonably foreseeable new affected environment consistent with climate change. Inasmuch as this project is related to Probabilistic Flood Hazard Assessment (PFHA) (a safety perspective), environmental topics are not pursued further outside of preliminary characterization. 
Table 1.1. Matrix of NRC's assessment topics and prioritized climate change information needs.

\begin{tabular}{|c|c|c|c|c|c|c|c|c|}
\hline & \multicolumn{2}{|c|}{$\begin{array}{l}\text { NRC } \\
\text { Need }\end{array}$} & \multicolumn{6}{|c|}{$\begin{array}{c}\text { Climate Change Information } \\
\text { Needs }\end{array}$} \\
\hline Topic & $\begin{array}{l}\vec{I} \\
\vec{z} \\
\frac{0}{0} \\
\stackrel{0}{0} \\
\tilde{n}\end{array}$ & 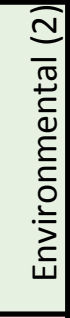 & 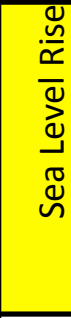 & 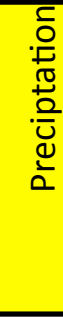 & 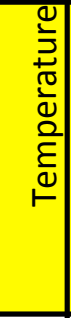 & 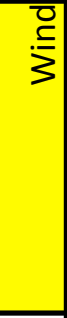 & 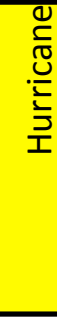 & 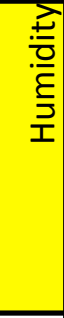 \\
\hline Local Intense Precipitation & (1) & (3) & 3 & 1 & (2) & 3 & & \\
\hline River Flooding & (1) & 2 & 3 & 1 & 2 & 3 & & 3 \\
\hline Drought & (3) & (1) & & 1 & 2 & (3) & & 3 \\
\hline Tsunami & (1) & & 1 & & & & & \\
\hline Storm Surge & (1) & 2 & (1) & & & & 1 & \\
\hline Alternative Cooling Systems & & 2 & & & (1) & & & 2 \\
\hline Cooling System Performance & 2 & 2 & & & (1) & & & \\
\hline Stream Temperature & & 2 & & & (1) & 2 & & \\
\hline Alternative Energy & & (3) & & & (1) & (1) & & \\
\hline Energy Demand & & 3 & 2 & 2 & (1) & & & \\
\hline Forecasting & 2 & 3 & 2 & 1 & (1) & 2 & 2 & \\
\hline Water Quality & & (1) & (1) & (1) & (1) & & & \\
\hline Wind Load & (1) & & & & & 12 & & \\
\hline
\end{tabular}

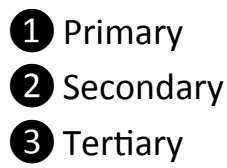

Currently, NRC hydrology safety analyses are deterministic, stylized, and conservative. With PFHA on the horizon, the climate change information must be embedded in the distributions of meteorological parameters used in the PFHA (Monte Carlo simulations). The distributions reflect both aleatory and epistemic uncertainty with climate change an element of the uncertainty. Currently, distributions for events with annual exceedance probabilities in excess of once in 1,000 years do not exist for precipitation and other meteorological parameters. Wide error bands are expected, commensurate with the large aleatory and epistemic uncertainties, without regard to climate change. Climate change may or may not be a significant contributor to the overall uncertainty. However, it is likely that the improved climate system understanding being developed with climate change research models will help develop better conceptual models of climate systems that will be critical to developing exceedance curves for rare events. The existing deterministic hydrology and hydraulic models are likely to be used in the PFHA framework. However, the overall input to PFHA analysis will be probability distributions with associated uncertainties and not the current deterministic approach. 
Table 1.2. NRC and climate information needs related to local intense precipitation.

\begin{tabular}{|c|c|c|}
\hline \multicolumn{3}{|c|}{ Local Intense Precipitation } \\
\hline \multirow[b]{3}{*}{$\begin{array}{l}\text { NRC } \\
\text { Need }\end{array}$} & Definition & $\begin{array}{l}\text { Local Intense Precipitation is a realtively short duration event where } \\
\text { the concern is onsite and adjacent offsite flooding. }\end{array}$ \\
\hline & Safety & $\begin{array}{l}\text { Protection of safety-related structures from flooding during an } \\
\text { intense local precipitation event generally considers an event with in } \\
\text { excess of } 1,000 \text { year return frequency. }\end{array}$ \\
\hline & Environmental & $\begin{array}{l}\text { Typical standard engineering design for stormwater runoff systems } \\
\text { requires designing structures and systems (culverts, retention ponds } \\
\text { etc) for a rainfall event with a } 20 \text { year frequency without causing } \\
\text { adverse impacts to adjacent waterways. Erosion is a primary concern } \\
\text { with water leaving an area through a concentrated relase point that } \\
\text { drains a large area with impervious surfaces. Since this is a well } \\
\text { developed design question and is typical of any large commercial } \\
\text { facility, it is usually a tertiary concern in environmental licensing } \\
\text { reviews. }\end{array}$ \\
\hline \multirow{6}{*}{$\begin{array}{l}\text { Climate } \\
\text { Info } \\
\text { Need }\end{array}$} & Sea Level Rise & $\begin{array}{l}\text { For coastal site, SLR may result in a change in backwater boundary } \\
\text { conditions. Consideration of concurrent storm surge (for instance, LIP } \\
\text { with hurricane) is typically greater than SLR. And SLR is projected to } \\
\text { occur gradually. }\end{array}$ \\
\hline & Precipitation & $\begin{array}{l}\text { Primary interest is in a detectable shift in extreme precipitation for } \\
\text { the respective frequencies of safety and environmental reviews ( } 4 \sigma \\
\text { and } 2 \sigma \text { ) }\end{array}$ \\
\hline & Temperature & $\begin{array}{l}\text { Temperature of antecedent precipitation and event precipitation can } \\
\text { result in snow and ice that can transform the drainage landscape and } \\
\text { clog ditches, drains, and culverts. }\end{array}$ \\
\hline & Wind & $\begin{array}{l}\text { Wind can cause water surfaces to increase in downwind directions } \\
\text { and trigger wind waves and associated wave runup onto the site. }\end{array}$ \\
\hline & Hurricane & $\begin{array}{l}\text { Hurricanes as manifest extreme events can result in storm surge. } \\
\text { However, this is considered separately in the storm surge topic. }\end{array}$ \\
\hline & Humidity & $\begin{array}{l}\text { The short duration of LIP events makes humidity and evaporation of } \\
\text { insignificant interest. }\end{array}$ \\
\hline
\end{tabular}

Recent advances in deterministic hydrologic modeling have been predominately driven by advances in information technology (IT) resources and the need to support assessments of impacts of climate change on water resources. Enhanced data management infrastructure and new spatial data products (including remotely sensed information) have allowed more rapid and automated data assimilation into hydrologic models. To assimilate products provided by the climatological community as inputs to hydrologic analyses, the hydrologic community has recently developed capabilities to provide meteorological records with multivariate coherence in space and time. With these capabilities, the current suite of hydrologic simulation models is able to generate meaningful flow records based on the climate results. In addition, grid development for many one- and multi-dimensional hydrological models is now fully automated in front-ends to many standard hydrologic models. Thus the time and cost associated with model setup have been greatly reduced. This setup efficiency, along with improved IT resources, allows for ensemble runs with deterministic models to develop probabilistic outcomes more consistent with the NRC's probabilistic, risk-informed Regulations.

From the NRC safety perspective, climate research is unlikely to provide direct information at annual exceedance probability level of 0.001 or less in the near future. However, an improved understanding of large-scale climate pattern changes (e.g., the occurrence of extreme precipitation events such as atmospheric rivers, rain, on snow with frozen soil) can help inform the probabilistic characterization (i.e., likelihood) of extreme events. 



\subsection{Recent Scientific Findings on Climate Change}

Spanning the Pacific and Atlantic coasts with mountains and plains in between, the United States is marked by diverse climate regimes that exhibit large variability from sub-daily to decadal time scales. Figure 2.1 highlights some key climatic features relevant to the climate information needs identified in Table 1.1. In the west, California and the Pacific Northwest receive most of their precipitation during the cold season, with the orographic forcing from mountains playing a key role in amplifying precipitation from the Pacific storms and producing snowpack at high elevations that becomes a natural reservoir of water released in spring and summer. Atmospheric rivers (i.e., narrow filaments of abundant moisture transported across the subtropics to the mid-latitudes) are main producers of heavy precipitation and floods. Despite the frequent winter storms, California is prone to droughts as the storm tracks are influenced by large-scale circulation patterns that vary on interannual to decadal time scales. Further inland in the intermountain west, both winter and summer storms may be responsible for flooding. The complex terrain has a strong influence on precipitation seasonality and flood characteristics. The Southwest is influenced by the North American monsoon that brings warm moist air and convective storms in the summer. This region, however, is generally arid as it is under the influence of the subtropical high-pressure system; thus, seasonal and multi-year droughts are of concern.

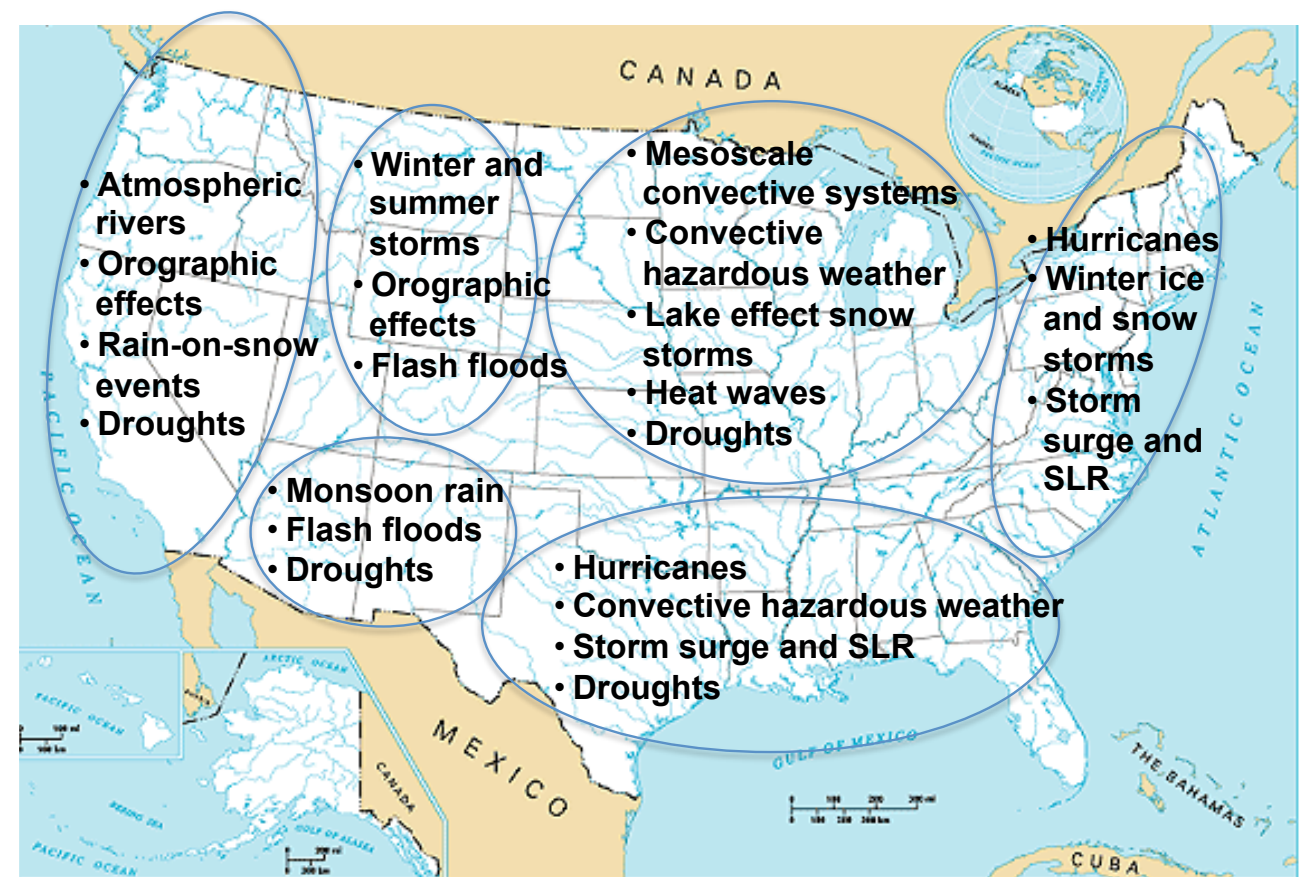

Figure 2.1. Regional climatic features in the conterminous U.S. relevant to the NRC's climate information needs.

In the central U.S., abundant moisture is supplied by a low-level southerly flow from the Gulf of Mexico, which helps maintain mesoscale convective systems (MCSs) propagating from Rocky Mountains across the Great Plains, producing heavy precipitation. The moist environment and the wind shear are conducive to hazardous weather (e.g., tornadoes). In the northern Great Plains, lake-effect snow storms can generate heavy snowfall in the Great Lakes region. However, the Midwest is also prone to heat waves and droughts in the summer when high-pressure systems stagnate for prolonged periods. In the Gulf Coast and eastern United States, storm surges associated with hurricanes are significant threats to coastal inundation. Severe winter ice and snow storms are important climatic factors along the Atlantic coast. 
Since the Intergovernmental Panel on Climate Change's (IPCC's) Fifth Assessment Report (AR5), important advances in understanding and projecting future climate changes have been made using theories and modeling. Climate model outputs from the Coupled Model Intercomparison Project Phase 5 (CMIP5) (Taylor et al. 2012) that feature historical and future climate simulations by a large ensemble of multi-models remain highly utilized in climate research, while new modeling experiments specifically designed by individual researchers or modeling centers supplement the standard CMIP5 simulations to investigate specific mechanisms of regional impacts of global warming. In what follows, we summarize some key findings from recent literatures, with a focus on the extremes for different climate variable relevant to NRC's climate information needs.

\subsection{Temperature}

\section{Temperature changes}

- Projected larger increases in daily minimum temperature than daily maximum temperature

- Larger warming in 'business-as-usual' than mitigation scenarios

- A shift in daily maximum surface temperature can lead to increase in heat wave intensity and frequency in the future

- Hot extremes are projected to intensify over much of the United States, with drying amplifying the severe hot and dry conditions

- Although cold extremes may still occur in the future, models project robust reduction in frequency of cold air outbreaks as polar amplification reduces cold air advection into the midlatitudes

Surface air temperature is projected to increase in the future as greenhouse gases continue to accumulate in the atmosphere from emissions in the past and emission scenarios projected for the future. Extreme temperatures have been investigated using the Expert Team on Climate Change Detection and Indices (ETCCDI) (Alexander et al. 2006). The ETCCDI indices are designed for detecting and attributing human effects on extreme weather, but they do not represent particularly rare events. Extreme value statistical methodologies can be applied to quantify the behavior of the tails of the distribution of certain ETCCDI indices and provide insights on truly rare events (Brown et al. 2008; Peterson et al. 2013). Climate models projected larger increases in daily minimum temperature than daily maximum temperature, and the warming is larger for the "business-as-usual" emission scenario RCP8.5 than the emission scenario RCP4.5 with mitigation. The northern high latitude regions show the strongest increase in minimum daily minimum temperature, while changes in the maximum daily maximum temperature tend to be evenly distributed globally (Sillmann et al. 2013).

For North America, the winter increase in cold nights has large changes in northern United States corresponding to snow covered areas in the present climate. Cool nights in the summer show warming that increases from the coast towards the continental interior. Winter increases in warm days are projected to be significantly less than winter cold nights, with an apparent poleward gradient. Summer hot days are projected to warm slightly more than summer cool nights (Figure 2.2). Seasonality in the projected changes reflects the complex mechanisms affecting changes in extreme and mean temperatures. For example, changes in snow cover affect the future winter mean and extreme temperatures, and decreases in soil moisture affect the future summer mean and extreme temperatures, thus creating warming patterns reflecting the modulating effects of the land surface on air temperatures. 


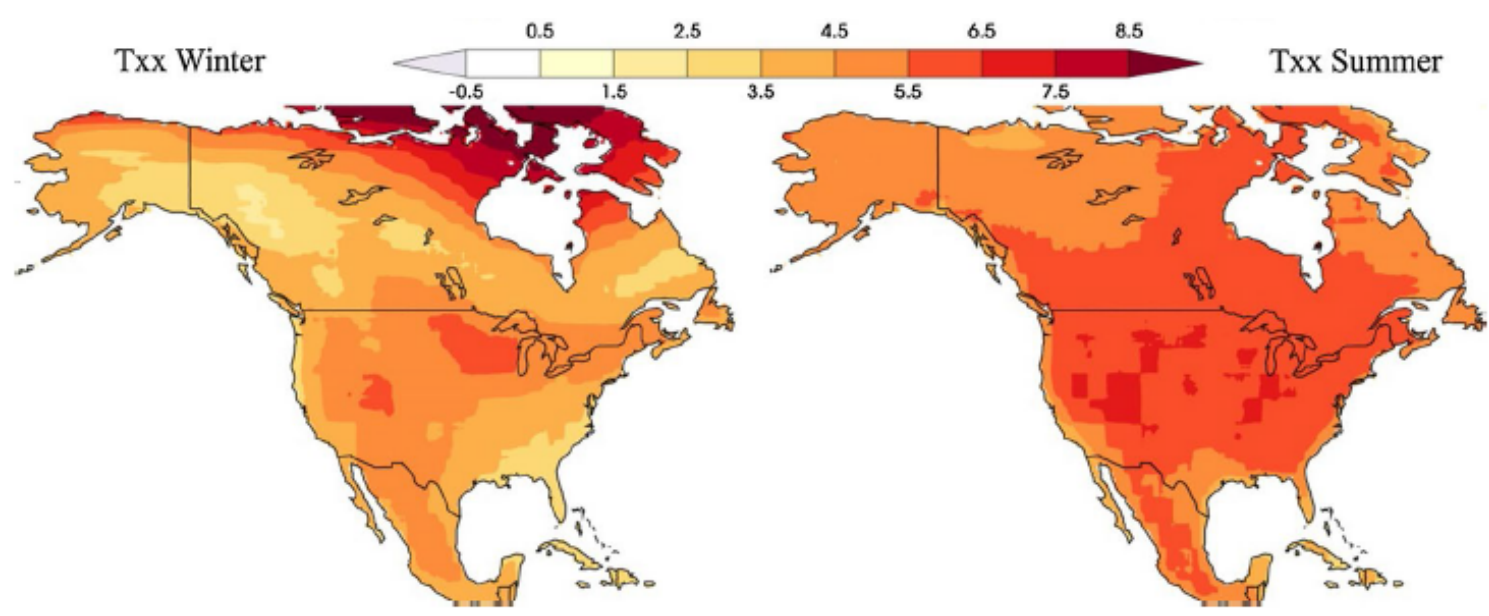

Figure 2.2. Changes in temperature of extreme hot days (i.e., seasonal maximum of maximum daily temperature [Txx]) for winter (left) and summer (right) comparing 2080-2100 and 19852005 from the CMIP5 model projections following the RCP8.5 (business-as-usual) scenario (Grotjahn et al. 2015).

Changes in large-scale circulation (e.g., a shift towards a more westerly circulation or changes in the frequency or patterns of blocking events) may influence extreme temperature (van Oldenborgh et al. 2009; Sillmann and Croci-Maspoli 2009). In the United States, Lau and Nath (2012) noted that the probability distribution functions (PDFs) for the current and future climate over most regions that experience heat waves have similar shape except for a shift by the mean warming in the daily maximum temperature. The skewness of the PDFs exhibited only minor changes from the current to future climate. Hence, the increase in heat wave intensity and frequency in the future is primarily associated with a shift in the daily maximum surface temperature, with changes in large-scale circulation likely playing only a minor role. However, Diffenbaugh and Ashfaq (2010) found that hot extremes will intensify over much of the United States in association with a summer anticyclonic circulation anomaly in the future, which will reduce precipitation and soil moisture, and amplify severe hot and dry conditions. These changes were more prominently simulated in regional models that better resolve climatological variations.

For cold air outbreaks (CAOs), Schneider et al. (2015) and Gao et al. (2015a) both found that the mean warming and the reduced temperature variance due to polar amplification account for most of the decrease in CAOs in a warmer climate. For North America, Gao et al. (2015a) further found that changes in temperature skewness associated with changes in blocking frequency and thermodynamical modulation by melting of snow and sea ice along the $0^{\circ} \mathrm{C}$ isotherm contribute to regional differences in CAO changes.

Overall, some robust changes in temperature extremes have emerged from analysis of the CMIP3 and CMIP5 multi-model ensembles. In general, model projections indicate increased frequency, intensity, and duration of heat waves and that, despite global warming, cold extremes may still occur in some regions due potentially to changes in blocking events and thermodynamic effects of snowmelt (Vavrus et al. 2006; Gao et al. 2015a). Some public perception posits that CAOs may become more extreme because of the weakened jet stream that allows high-amplitude eddies and increases the likelihood of blocking episodes (Francis and Vavrus 2012; Cohen et al. 2014). However, recent studies based on model simulations and theory showed no signs of more frequent or extreme CAOs, as polar amplification reduces the meridional temperature gradient and hence, significantly reduces cold air advection into the mid-latitudes. Analysis of northern hemisphere blocking in climate simulations using three blocking identification methods also showed no clear increase in blocking frequency due to polar amplification, as suggested to be the mechanism for increasing CAOs in the future (Barnes et al. 2014). 
To reduce uncertainty in projecting extreme temperature changes in the future, more detailed analyses using multi-model ensembles may provide further insights on the mechanisms of heat wave changes associated with land-atmosphere coupling. In the Great Plains, there are well-known large warm biases in model simulations of summer temperature, which have been linked to model deficiency in simulating precipitation associated with mesoscale organized convection (Klein et al. 2006). Hence, improving model simulations of convection and regional precipitation may be key to constraining the role of landatmosphere interactions on extreme warm temperature changes in the future. Lastly, some uncertainty remains in potential changes in large-scale circulation patterns (e.g., blocking) that affect both heat waves and CAOs. Well-designed climate modeling experiments combined with observational analyses that target specific mechanisms and hypotheses may help isolate different factors and provide constraints for more robust projections of extreme temperature changes.

\subsection{Precipitation (and Humidity)}

\section{Precipitation changes}

- Globally precipitation is projected to increase at about $2 \% \mathrm{~K}^{-1}$ warming

- Extreme precipitation is projected to increase more than mean precipitation; in the extratropics, the increase is roughly $5 \%$ to $6 \% \mathrm{~K}^{-1}$ warming

- In the western United States, flooding is primarily associated with atmospheric rivers, which are projected to increase by $50 \%$ to $600 \%$ in frequency in the west coast of North America

- Changes in extreme precipitation associated with warm season convection are more uncertain but analysis of observational records provided some evidence of extreme convective precipitation increasing by more than $7 \% \mathrm{~K}^{-1}$

- Although warmer temperature in the future reduces mean snowfall in general, extreme snowfall should increase due to competition between increasing saturated specific humidity and decreasing snowfall fraction with warmer temperature

- Increasing saturation deficit over land should drive a general increase in aridity over land in a warmer climate; more specifically climate models robustly projected significant increase in drought risks in southwestern and central United States driven primarily by increased evaporation

Climate models projected warmer temperatures in the future as a result of increasing concentrations of greenhouse gases. Following the Clausius-Clapeyron (CC) relationship, the atmosphere can hold about 6 to 7 percent more moisture for each degree $\mathrm{K}$ of warming, or more precisely, the saturation vapor pressure increases by 6 to 7 percent per degree $\mathrm{K}$ of warming. Changes in evaporation are energetically constrained by changes in processes related to near-surface relative humidity. By relating the fractional change in relative humidity to the fractional change in saturation-specific humidity and fractional change in evaporation, it can be inferred that near-surface relative humidity changes very little with temperature (Schneider 2010). As precipitation is balanced by evaporation globally, the increase in precipitation is constrained by the change in evaporation, which relates directly to surface latent heat flux that is energetically constrained by the radiative forcing. Hence, unlike water vapor or precipitable water, which increases by 6 to 7 percent per degree K of warming, climate models projected only an approximately 2 percent increase per degree $\mathrm{K}$ warming for global precipitation and evaporation (Held and Soden 2006). Regionally, precipitation changes can vary significantly depending on the changes in the large-scale circulation. For example, climate models projected expanded drying in the subtropics associated with the 
subsiding branch of the Hadley circulation, which is projected to weaken and expand poleward (Vecchi and Soden 2007; Lu et al. 2007). Climate models also projected poleward shifts of the storm tracks in response to the meridional temperature gradient change (Chang et al. 2012), giving rise to dipole changes in extratropical precipitation on the poleward and equatorward sides of the storm tracks.

Extreme precipitation is projected to increase more than mean precipitation. This is because extreme precipitation is not energetically constrained as precipitation by evaporation from the surface. Several factors could contribute to changes in extreme precipitation in the future. These include dynamical contributions from changes in vertical motion, thermodynamical contributions from changes in saturation-specific humidity, and microphysical contributions from changes in precipitation efficiency. In the extratropics, vertical motion in non-convective environments (e.g., frontal systems) is constrained by the planetary rotation, so its changes are relatively small. Hence, thermodynamical contributions play a dominant role and extreme precipitation increases by approximately 5 to 6 percent per degree $\mathrm{K}$ of warming in the extratropics (Figure 2.3). Similar to mean precipitation, however, regional changes in extreme precipitation vary by season and location. In the cold season, poleward shifts in the storm tracks appear to shift both the mean and extreme precipitation poleward (O'Gorman and Schneider 2009; Lu et al. 2014).

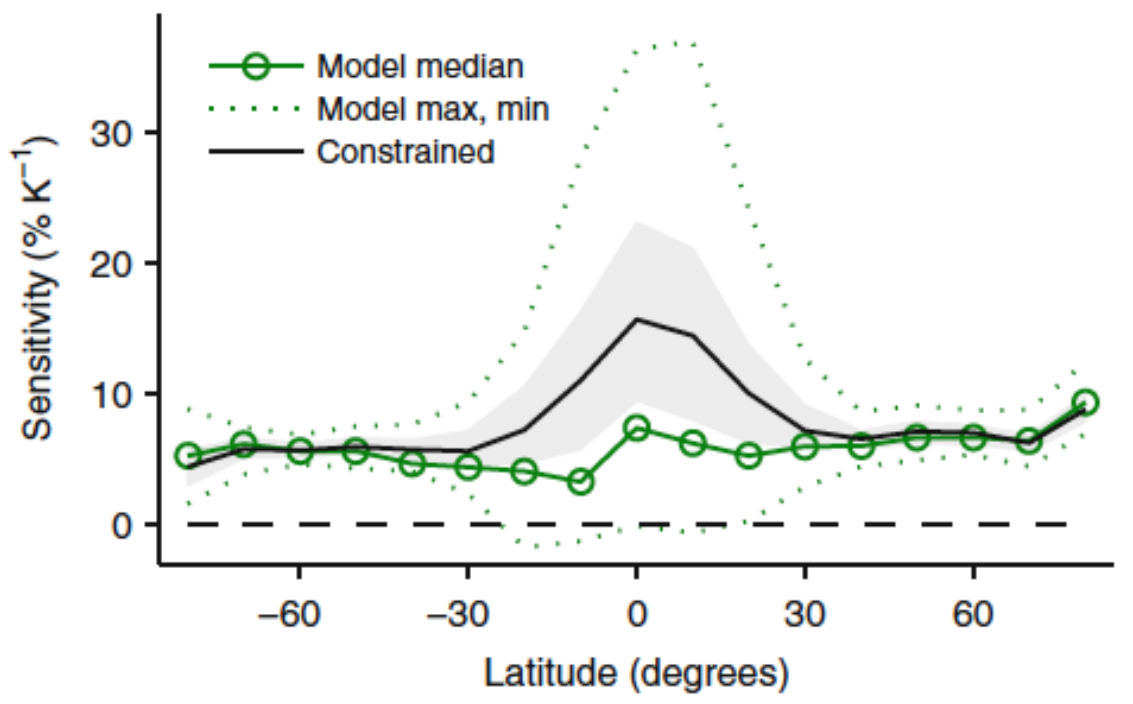

Figure 2.3. Changes in $99.9^{\text {th }}$ percentile daily extreme precipitation from CMIP5 models, showing a general increase of about 7 percent per degree $\mathrm{K}$ of warming in the extratropics but larger uncertainty in the tropics (O'Gorman 2015).

Extreme precipitation in the western United States is dominated by atmospheric rivers (ARs), which are narrow corridors responsible for over 90 percent of the poleward transport of water vapor globally (Zhu and Newell 1998). When ARs from the North Pacific make landfall at the coastal western United States, they can bring record-setting precipitation leading to floods (Dettinger 2011; Ralph et al. 2006; Leung and Qian 2009, Neiman et al. 2011). On the other hand, ARs can also have benevolent impacts by relieving droughts (Dettinger 2013). Following the CC relationship, AR frequency could increase as climate warms. Using CMIP3 results, Dettinger (2011) found the number and intensity of winter ARs making landfall in California roughly unchanged, but the number of ARs with water vapor transport much larger than historical increases. Warner et al. (2015) found an almost three-fold increase in the number of days with vertically integrated vapor transport above the historical $99^{\text {th }}$ percentile along the west coast of North America. Consistent with these results, Gao et al. (2015b) revealed a strikingly large increase (i.e., between 50 and 600 percent) of AR days by the end of the $21^{\text {st }}$ century in the RCP8.5 scenario. Gao et al. 
(2015b). They further quantified the dynamical and thermodynamical contributions associated with winds and water vapor, respectively, to the change in AR frequency and found that the latter contributes predominantly to the increase in AR frequency, while wind changes limit the increase in AR days (Figure 2.4). The negative effect of wind changes on AR days in spring and fall is linked to be robust poleward shift of the subtropical jet in the North Pacific basin. Overall, these results consistently point to the likelihood of increasing frequency of AR in the future. Following the discussion of extreme precipitation changes, the enhanced water vapor with warming may increase extreme precipitation associated with ARs following roughly the $\mathrm{CC}$ rate.
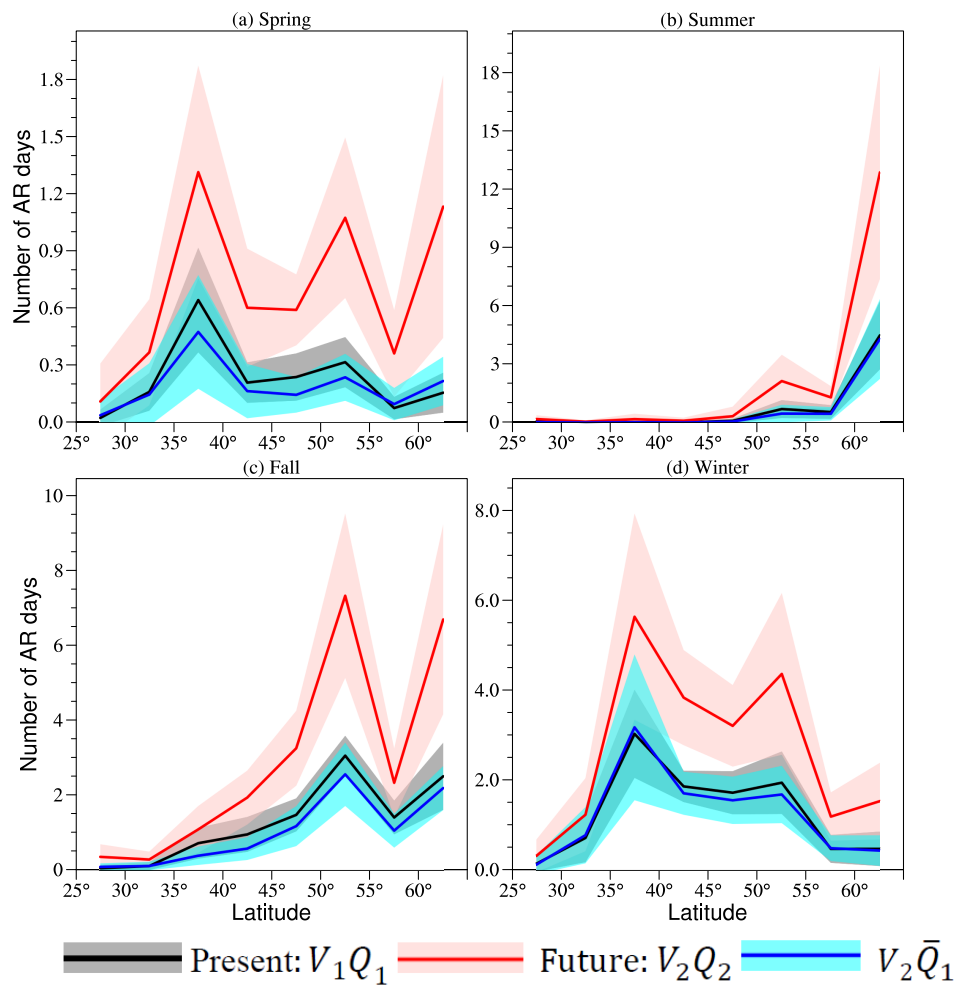

Figure 2.4. Number of AR days from CMIP5 simulations for the present (grey), future (pink), and for AR detected by scaling the future simulations with the present-day atmospheric moisture (blue) comparing the two decades near the end of the $21^{\text {st }}$ and $20^{\text {th }}$ centuries in the RCP8.5 scenario (Gao et al. 2015).

Despite improved understanding of extreme precipitation changes in the extratropics during cold season, large uncertainty remains in projecting changes in extreme precipitation in the tropics or during warm season in the extratropics dominated by convection. A main reason for this uncertainty is the uncertainty in parameterizing convection in climate models. This issue is particularly acute in the central United States where MCSs are dominant mechanisms for producing heavy precipitation. Climate models that rely on convective parameterizations are known to be highly deficient in simulating the propagating MCSs that produce nocturnal peak in precipitation in the Great Plains. A few studies (e.g., Kendon et al. 2014) that downscaled global climate projections using regional models at convection permitting resolution (i.e., at 1 to $4 \mathrm{~km}$ that explicitly resolves rather than parameterizes convection) suggest that convective extreme precipitation may increase at a super $\mathrm{CC}$ rate (i.e., greater than approximately 7 percent per degree $\mathrm{K}$ of warming) due to enhanced moisture combined with more vigorous convection in a warmer climate. Analysis of observed hourly precipitation data in Europe (Lenderink and van Meijgaard 2008; Berg et al. 2013) and the United States (Lepore et al. 2014) supports the super CC 
increase in extreme convective precipitation in contrast to extreme stratiform precipitation that roughly follows the CC rate (Figure 2.5).

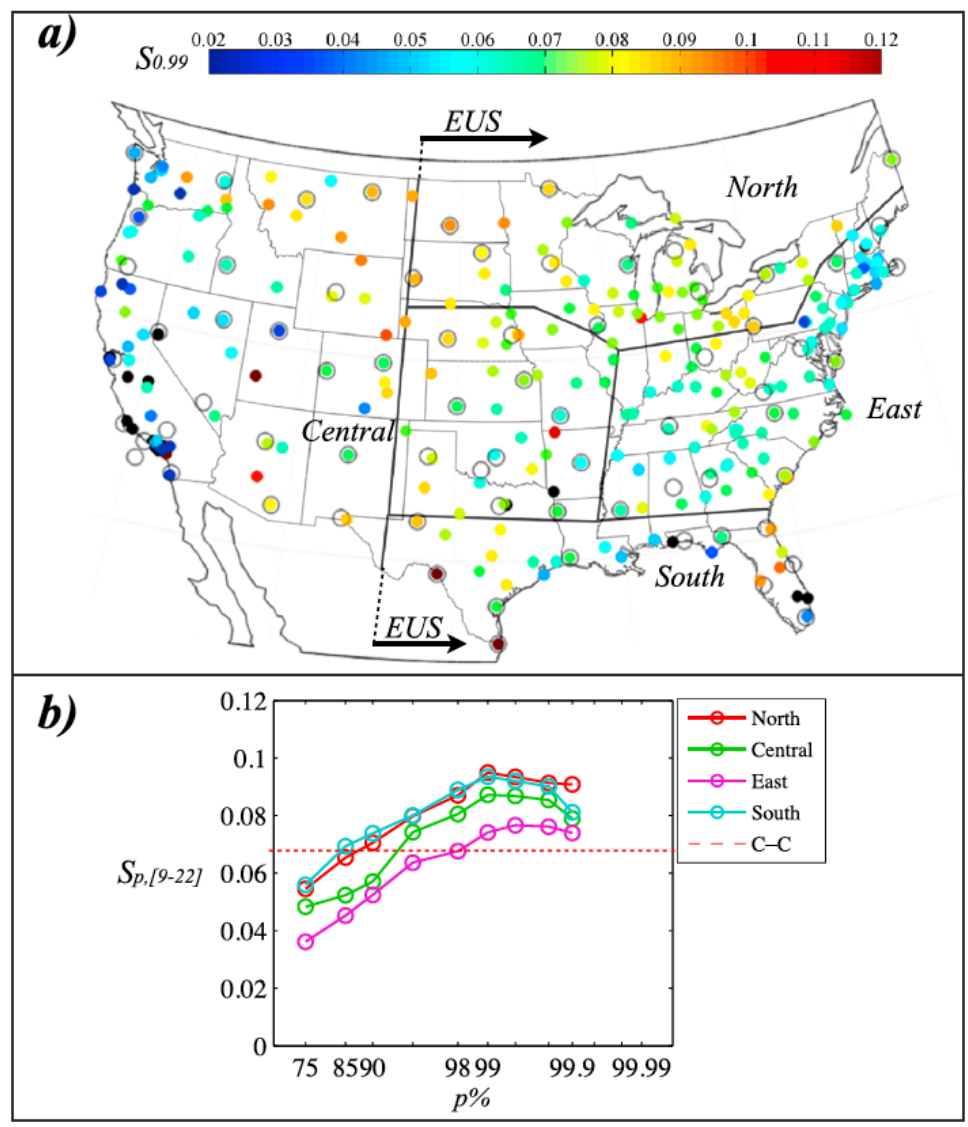

Figure 2.5. Sensitivity of the $99^{\text {th }}$ percentile hourly precipitation per degree $\mathrm{K}$ of warming $\left(\mathrm{S}_{0.99}\right)$ in the United States (upper) and the sensitivity for different percentile values $\left(S_{p[9-22]}\right)$ for four U.S. sub-regions showing increasing sensitivity with increasing percentile values (bottom) (Lepore et al. 2014).

Snowfall events are expected to decrease in a warmer climate due to changes in the precipitation phase with warmer temperatures. However, O'Gorman (2014) found that changes in extreme snowfall would be more muted compared to snowfall events. This is because extreme snowfall occurs at an optimal temperature $\left(\sim-2.3^{\circ} \mathrm{C}\right)$ that is determined by the competition between increasing saturation-specific humidity and decreasing snowfall fraction with increasing temperature. This optimal temperature is insensitive to warming. Hence extreme snowfall is projected to decrease by only 8 percent compared to 65 percent for mean snowfall by the end of the $21^{\text {st }}$ century in the RCP8.5 scenario (Figure 2.6). This muted response of extreme snowfall suggests that extreme snowfall events such as those that occur in the eastern United States may continue in the future and that reduction in extreme snowfall may not be used as early signs to detect warming, as would be inferred from the sensitivity of snowfall to temperature.

Climate change may alter precipitation characteristics on both ends of the extreme through increase of frequency and intensity of extreme precipitation and droughts (Trenberth et al. 2004). While an increase in atmospheric water-holding capacity plays a major role in enhancing extreme precipitation in a warmer climate, increase in evaporation is an important factor in amplifying and prolonging droughts in the future. Land surface warms on average 50 percent more than ocean surface, but water vapor content over land does not increase fast enough to meet the evaporative demand. This is because water vapor over land 
is mostly supplied by the ocean, which increases at the $\mathrm{CC}$ rate corresponding to the smaller warming over the ocean (Sherwood and Fu 2014). Hence, the increasing saturation deficit over land should drive a general increase in aridity over land in a warmer climate.

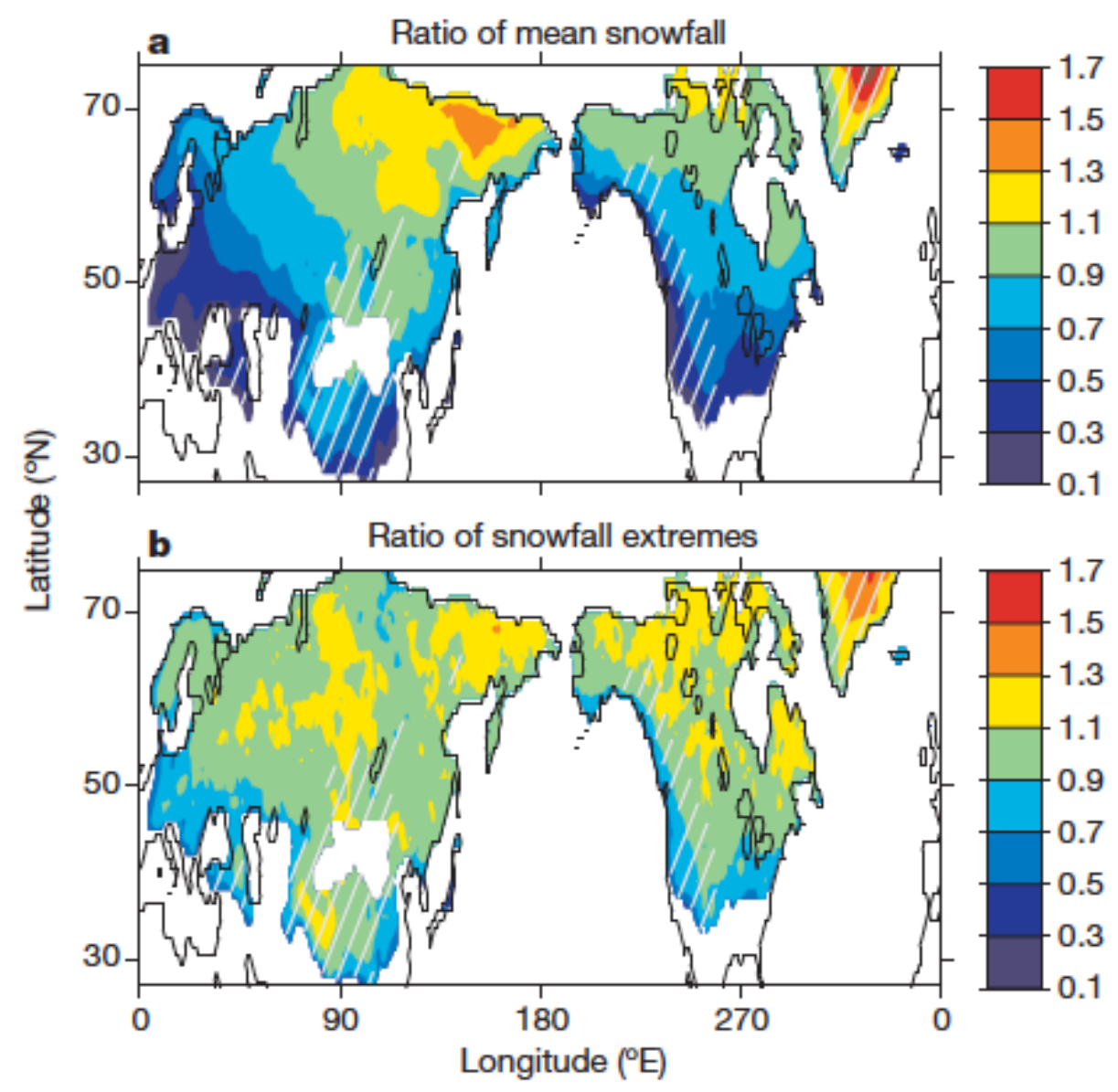

Figure 2.6. The ratio of future to present mean snowfall (upper) and snowfall extremes (bottom) showing much larger reduction from present to future for mean snowfall than snowfall extremes (O'Gorman 2014).

Historically, U.S. droughts have been largely attributed to interannual and interdecadal variations of sea surface temperature patterns in the Pacific and Atlantic oceans that shift storm tracks and anticyclonic pressure centers through teleconnections (Hoerling and Kumar 2003), with the land surface amplifying the response through soil moisture-precipitation feedbacks. Global climate models projected an imminent transition to more arid conditions comparable to megadroughts of the past in the southwestern United States (Seager et al. 2007), largely driven by the mean circulation of the subtropical high diverging more moisture from the warmer temperature away. Strengthening/expansion of the subtropical high pressure over the Pacific Ocean ( $\mathrm{Li}$ et al. 2012) also contributes to the drying (Seager et al. 2010), and an additional role of poleward storm track shifts in enhancing drying in the Southwest has been suggested (Gao et al. 2012; Gao et al. 2014). Using paleoclimate records to benchmark global climate models simulations of historical droughts, Cook et al. (2015) showed that the Palmer Drought Severity Index simulated by global climate models for the historical period of 1931 to 1990 is indistinguishable from observations, despite some significant deviations in some models. Cook et al. (2015) further showed that despite the diverse response of the models in their ability to capture atmosphere-ocean dynamics and teleconnections, they consistently projected significant drought risks in southwestern and central United 
States in the future (Figure 2.7), driven primarily by increased evaporation in conjunction with reduced precipitation or overcompensating the increased precipitation.

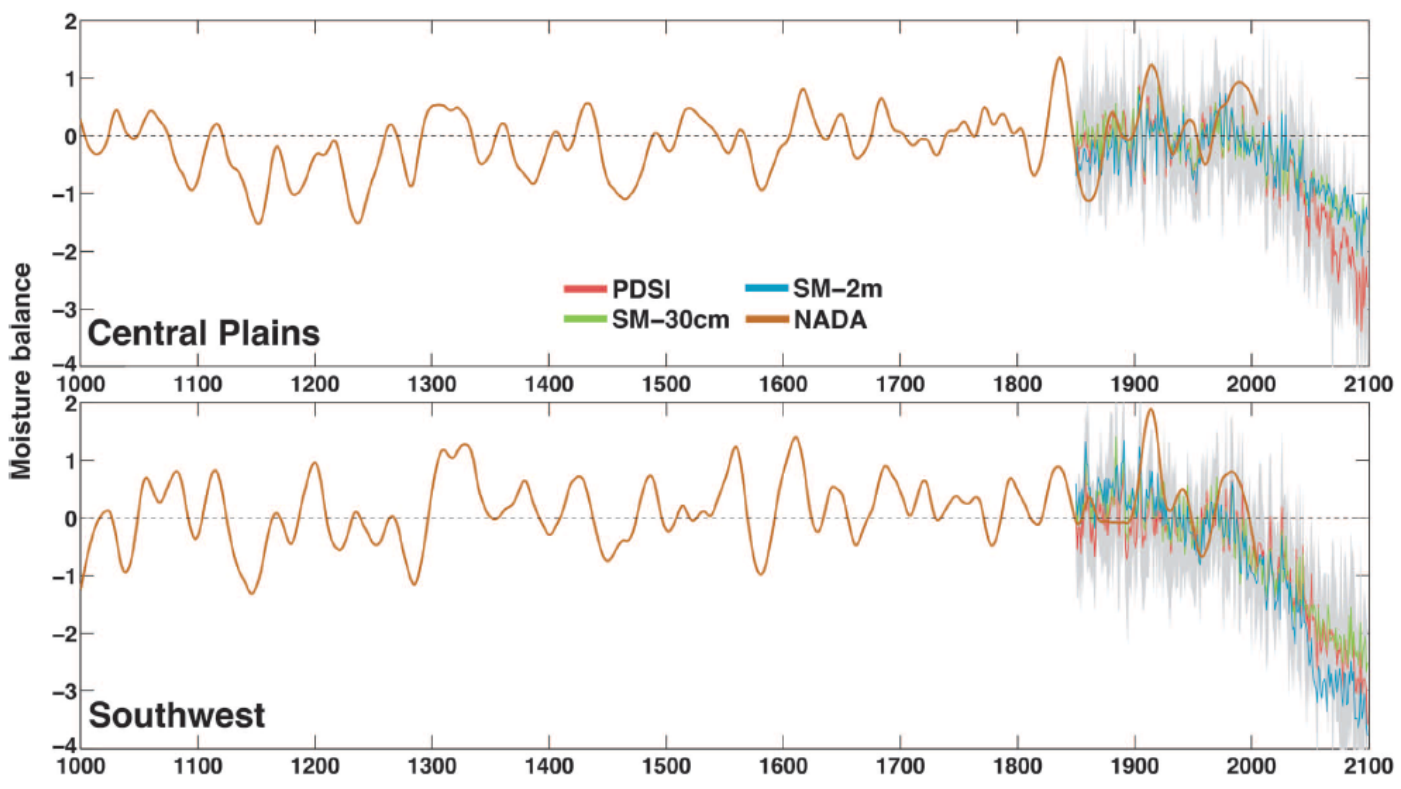

Figure 2.7. PDSI from North American Drought Atlas (red) and CMIP5 models (red), and soil moisture at $30 \mathrm{~cm}$ (green) and $2 \mathrm{~m}$ (blue) from CMIP5 models for the Central Plains and Southwest regions of North America (Cook et al. 2015).

Overall, understanding of the changes in mean and extreme precipitation has progressed in the last decade based on analysis of multi-model simulations to determine the robust changes, combined with theoretical understanding aiming at explaining the robust changes. In the climate science literature, extreme precipitation is typically defined as the $95^{\text {th }}$ and $99^{\text {th }}$ percentile daily precipitation value. Some studies have also investigated the changes in $99.9^{\text {th }}$ and $99.99^{\text {th }}$ percentile daily precipitation based on idealized simulations (e.g., aquaplanet simulations) (e.g., O'Gorman and Schneider 2009; Lu et al. 2014). In these simulations, zonal and hemispheric symmetry allows more robust statistical estimates of the $99.9^{\text {th }}$ and $99.99^{\text {th }}$ percentile values by constructing a space-time cumulative distribution function of daily precipitation (e.g., Sugiyama et al. 2010) to increase sample size from climate simulations, or by fitting the Generalized Extreme Value distribution to time series of annual maxima from climate simulations using probability-weighted moments instead of maximum-likelihood estimation because of the relatively short time samples (e.g., Kharin and Zwiers 2000).

As larger uncertainty in projecting changes in extreme precipitation is associated with extreme convective precipitation in the tropics and warm season events in the extratropics, regional models, global variable resolution models, and the multiscale modeling frameworks that explicitly resolve convection as well as development of scale aware parameterizations for convection are promising venues for advancing understanding and modeling of extreme precipitation in the warmer climate. These models may also produce more credible simulations of hourly and sub-hourly precipitation for studying higher temporal frequency extreme precipitation changes beyond daily extremes. As aridity and drought in the future may be driven more strongly by changes in evaporation than precipitation, and evaporation depends on temperature that models consistently project to increase, uncertainty in projecting drought risks tends to be smaller than uncertainty in projecting changes in extreme precipitation. However, uncertainty in the role of the land surface in amplifying droughts and uncertainty in large-scale circulation changes still need to be addressed to further constrain the projections of drought intensity and regional differences. 


\subsection{Hurricanes}

\section{Hurricane changes}

- Increases in ocean heat content in a warmer climate will generally increase hurricane intensity, and hence the frequency of high intensity storms

- Climate models do not project robust signal of Atlantic tropical cyclone frequency changes, but there are some consistent changes in storm intensity

- A poleward migration of the meridional position of lifetime-maximum intensity has been found in historical track data, which is consistent with the poleward shifts in vertical wind shear and potential intensity found in global reanalysis data

- Model projections of hurricane changes are uncertain; continued improvements in linking tropical cyclone activity to the large-scale environments and dynamical and statistical-dynamical downscaling are important for advancing insights on hurricane changes in the future

Hurricanes draw energy primarily from the ocean. In a warmer climate, hurricane intensity is projected to increase because the ocean heat content generally increases, thus increasing the frequency of the high intensity storms (Elsner et al. 2008, Knutson et al. 2010). Despite this general finding, model projections of hurricane changes are uncertain because of uncertainty in projecting changes in the ocean heat content; uncertainty in projecting changes in atmospheric environments (e.g., vertical wind shear, sea level pressure, and vorticity) that influence hurricane intensity, tracks, and genesis; and model deficiency in simulating tropical cyclones (TCs), partly because of the low resolution and limitations in physics parameterizations.

Three methods can be used to investigate changes in hurricane activities simulated by climate models. In the first method, TC detection and tracking algorithms are applied directly to model outputs to identify and track TC-like storms simulated by the models. These algorithms, which utilize dynamical and thermodynamical thresholds (e.g., thresholds for vorticity, wind speed, and local temperature anomaly), are adjusted based on statistics of the 6-hourly model outputs from the historical simulations to provide a reasonable climatology of TC activity for each model. The same thresholds for each model are then applied to the simulations of the future climate by the same model. The second method relates TC activity with large-scale environments resolved by climate models. The third method involves dynamical or statistical-dynamical downscaling to improve simulations of higher intensity TCs.

Applying TC detection and tracking algorithms to CMIP5 model outputs showed that models generally simulate too few TCs in the historical period (Camargo 2013). Although no robust signal of Atlantic TC activity changes was observed across models - consistent with projections using statistical downscaling methods (Villarini and Vecchi 2012) - dynamical downscaling suggested decreasing storm frequency (Knutson et al. 2013). However, CMIP5 models projected a statistically significant increase (decrease) in the percentage of storms for the subtropical (tropical) cluster, suggesting changes in tracks that may influence the likelihood of U.S. landfall. In general, the models projected increases in potential intensity (PI) - one indicator of TC activity based on the large-scale environment - in the northern hemisphere, with model differences at regional scale. Many models also projected an increase in vertical wind shear in the eastern North Atlantic and Caribbean region, but the eastern part of the Atlantic is marked by a reduction in wind shear. 
Despite uncertainty in projecting changes in the number of TCs, there are some consistent changes in TC intensity. Hence, an important question is how TC tracks have changed in the past and may change in the future and influence the frequency of U.S. landfalling hurricanes. Analysis of observed track data for 1982 to 2012 showed a poleward migration of the meridional position of lifetime-maximum intensity, which is consistent with the poleward shifts in vertical wind shear and potential intensity found in global reanalysis data (Kossin et al. 2014) (Figure 2.8). An assessment of future track changes is not likely to yield robust results as TC tracks are not reliably simulated by models. However, changes in large-scale environments may provide some insights on the likelihood of unusual tracks occurring again in the future. This question was investigated by Barnes et al. (2013) using the unusual track of Hurricane Sandy as an example. Sandy was steered onto the U.S. coast almost perpendicular to the coastline by unusual atmospheric conditions including an equatorward jet shift, a blocking anticyclone in the Atlantic, and associated Rossby wave breakings that steered Sandy along the anomalously cyclonic vorticity contour. Changes in the large-scale circulation projected by CMIP5 models (e.g., the poleward shift of the jet stream) suggest reduced likelihood for the atmospheric environment to steer another storm along Sandy's path, should a storm of similar intensity and genesis location occur in the future.
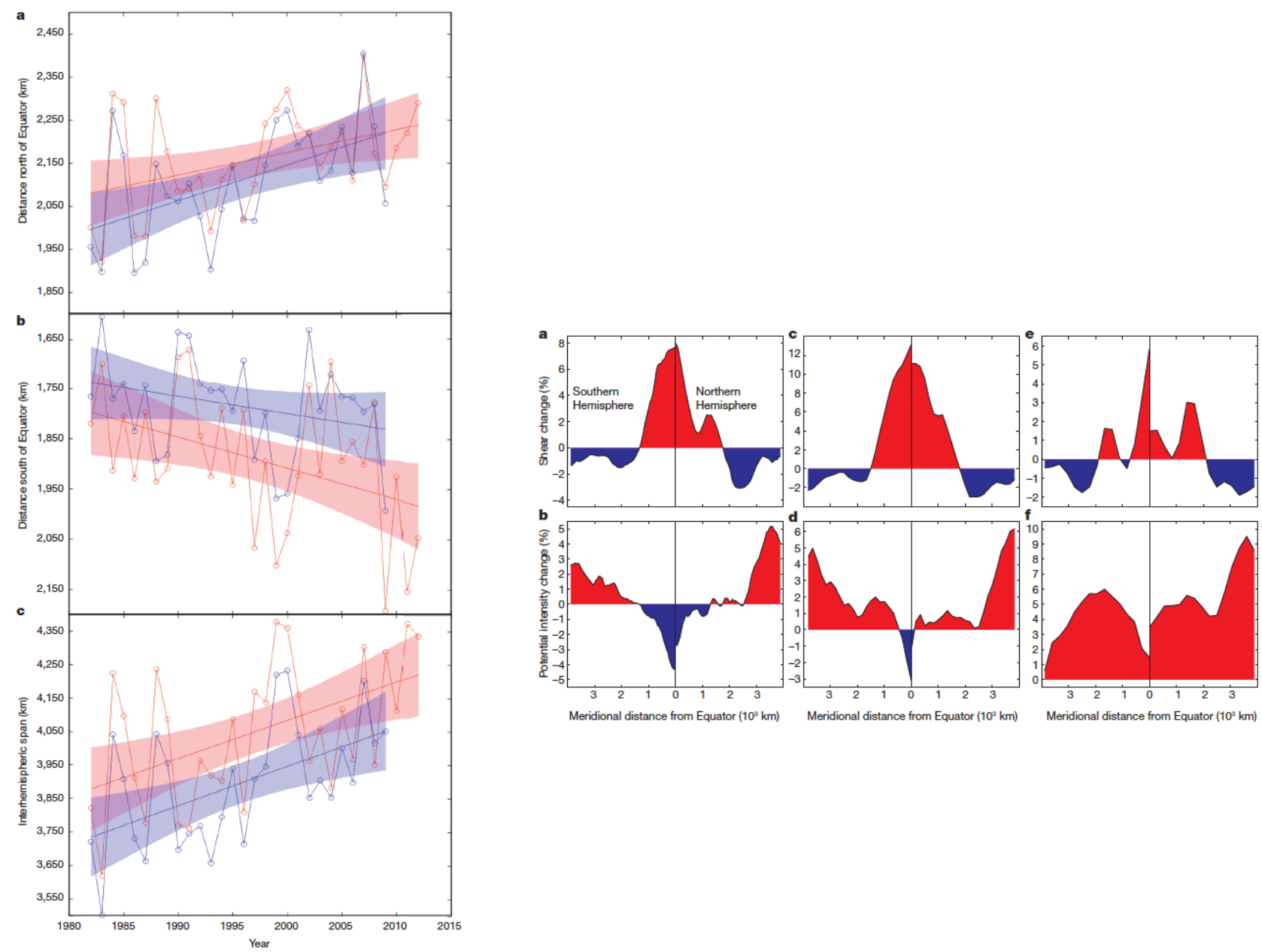

Figure 2.8. (Left) Poleward migration of the latitude of Lifetime-Maximum Intensity away from the tropics from the best-track historical data (red) and the ADT-HURSAT reanalysis (blue) in the northern (a) and southern (b) hemispheres, and their annual mean difference (c). (Right) Observed changes from 1980-1994 to 1995-2010 in the mean vertical wind shear (a, c, e) and potential intensity (b, d, f) where TCs form and track. Results are from three different reanalysis products (Kossin et al. 2014). 
As model resolution increases, climate models could simulate TCs more realistically to provide a more robust assessment of future TC changes. However, models in CMIP6 will not reach a resolution for significant improvement in TC simulations. Hence, continued improvements of all approaches in linking TC activity to the large-scale environment and dynamical and statistical-dynamical downscaling are important for advancing insights on hurricane changes. These methods also represent a more viable approach for providing TC information needed for modeling storm surge associated with TCs (e.g., Lin et al. 2012).

\subsection{Winds}

\section{Wind changes}

- Hazardous convective weather (HCW) is not resolved in current climate models, so projecting its changes has been advanced through understanding of the atmospheric environments favorable for its occurrence

- Three ingredients are important to support HCW that generates strong, damaging winds: vertical wind shear, strong updraft, and convection initiation

- Climate models generally projected an environment more favorable for HCW because of warmer and moister atmosphere, but a reduction in wind shear due to polar amplification may offset some of the changes

Strong, damaging winds that occur in the United States are most commonly associated with hurricanes and hazardous convective weather (HCW) (i.e., weather the produces tornadoes, hail, and damaging winds). Fundamental challenges in understanding and predicting $\mathrm{HCW}$ are related to limitations imposed by observational data that lack sufficient spatial and temporal resolution, and models that do not adequately resolve severe convection due partly to the coarse model resolution. Hence, research on projecting $\mathrm{HCW}$ changes in the future climate has advanced mainly through understanding of the atmospheric environments favorable for $\mathrm{HCW}$ occurrence and how such environments may change in a warmer climate. Three ingredients in the atmosphere are important to support HCW. First, vertical wind shear is an important control of the organization and longevity of severe convection. Second, the development of strong updraft requires energy governed by the thermodynamics of the atmosphere. Lastly, a process for convection initiation must be present to trigger severe convective events. The first two elements can be described by the bulk vertical wind shear between the surface and $\sim 6 \mathrm{~km}$ and the convective available potential energy (CAPE), respectively. However, characterizing convective initiation is more difficult because a variety of mechanisms can trigger convection and they are influenced by mesoscale to large-scale atmospheric environment as well as surface conditions. Indices based on wind shear and CAPE or similar thermodynamical parameters have some skill in capturing the seasonal and spatial variability of HCW occurrences (e.g., tornadoes) (Brooks et al. 2007; Tippett et al. 2012).

Analysis of historical data of atmospheric environments showed increasing trends in the frequency of the most extreme HCW in the United States over the last three decades (Sander et al. 2013). Climate model projections of $\mathrm{HCW}$ changes in a warmer climate generally indicate an increase in the atmospheric environment favorable for HCW (Trapp et al. 2007; Brooks 2013; Diffenbaugh et al. 2013; Tippett 2014; Seeley and Romps 2015), largely because of an increase in CAPE due to warmer temperatures (Del Genio et al. 2007) and associated increased saturation-specific humidity. Increasing CAPE is offset somewhat by a reduction of vertical wind shear due to the weaker meridional temperature gradient resulting from the polar amplification. In the United States, for example, Diffenbaugh et al. (2013) found the largest increase of 2 days per model grid point in favorable $\mathrm{HCW}$ by the end of the $21^{\text {st }}$ century occurring during spring due to the weaker reduction in wind shear compared to other seasons (Figure 2.9). 


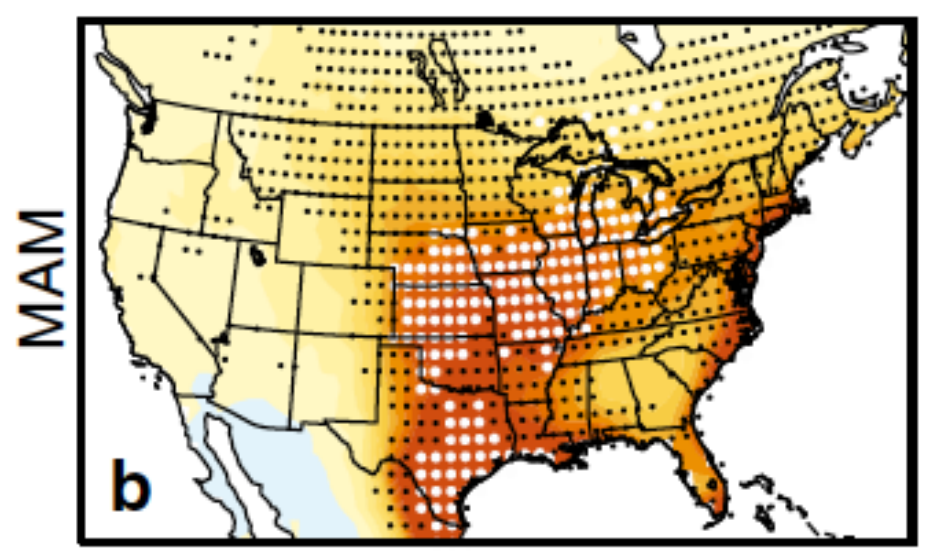

Figure 2.9. Changes in number of days with spring (March-April-May) severe thunderstorm environment (NDSEV) comparing 2070 to 2099 with 1970 to 1999 from CMIP5 models in the RCP8.5 scenario (Diffenbaugh et al. 2013).

A major source of uncertainty in projecting changes in $\mathrm{HCW}$ in a warmer climate is the reliance on relating $\mathrm{HCW}$ to the atmospheric large-scale environment, which does not explain all the variance in $\mathrm{HCW}$ in the historical records. Ignoring convection initiation and other factors (e.g., land-surface conditions) that also influence $\mathrm{HCW}$ is an important gap. With global climate models far from being able to resolve $\mathrm{HCW}$ in the near future, improving projections of HCW changes will rely on further advancing understanding of what controls HCW and improving simulations of the large-scale environments and other factors by climate models. There is also a potential for using regional climate models to advance both understanding of HCW and resolving HCW in dynamical downscaled projections of future climate (e.g., Gensini and Mote 2014).

\subsection{Sea Level Rise}

\section{Sea level rise}

- Between 1992 and 2013, the global mean sea level has increased at a linear trend of $3.3 \mathrm{~mm} / \mathrm{yr}$

- Regional sea level can differ significantly from the global sea level, with wind driven and buoyancy fluxes driven changes dominating regional sea level changes since the twentieth century

- For the United States, the median sea level rise in the $21^{\text {st }}$ century following the RCP8.5 scenario is highest in the Gulf Coast ( $>1 \mathrm{~m})$, followed by the eastern United States $(0.75 \mathrm{~m}-1 \mathrm{~m})$ where uncertainty is the largest due to uncertainty in atmosphere and ocean dynamics in climate models

The global mean sea level is governed by the change in the volume of water in the global ocean and the change in the shape of the ocean basin related to terrestrial land motion. On decadal time scales, changes in the volume of water are related to changes in density, which are produced by changes in temperature and salinity, and the water exchange between the ocean and reservoirs of continental hydrology including ice sheets, glaciers, ice caps, groundwater, and inland surface waters. Since 1992, sea level has been monitored continuously by satellite radar altimeters with sufficient accuracy to monitor regional and global trends. Satellite estimate of the linear trend of global mean sea level between 1993 and 2009 is $3.3 \mathrm{~mm} / \mathrm{yr}$ (Nicholls et al. 2010). 
Regional sea level can differ significantly from the global sea level due to regional differences in geological processes, the fingerprint effects of ice and ocean mass redistribution, and atmosphere and ocean dynamics. The latter has been a dominant driver of regional sea level changes, referred as dynamic sea level changes, since the twentieth century. Atmosphere and ocean processes responsible for dynamic sea level changes are either wind driven (i.e., mass redistribution by winds) or buoyancy-flux driven (i.e., changes in temperature, salinity, and freshwater fluxes).

Projections of future changes in global mean sea level are based on either a bottom-up assessment of different contributing factors or use a top-down method based on semi-empirical relationship between temperature and the rate of global mean sea level change. Projecting regional sea level requires a bottomup approach as different contributing processes can change very differently in the future. Global coupled atmosphere-ocean models are used to project dynamic sea level changes. Kopp et al. (2014) reported projections of regional sea level rise in the $21^{\text {st }}$ century following the RCP8.5 scenario. For the United States, the median sea level rise is highest in the Gulf Coast, with projected increases $>1 \mathrm{~m}$ except along the Florida coast (Figure 2.10). This is followed by the eastern United States, with projected increases generally between $0.75 \mathrm{~m}$ and $1 \mathrm{~m}$. The west coast sea level is projected to increase between 0.25 and $0.6 \mathrm{~m}$. Uncertainty in projected sea level changes is by far the largest along the East Coast. Globally, uncertainty in projecting sea level rise is largely related to uncertainty in ice sheet changes, as climate models are only beginning to represent ice sheet dynamics. In the eastern United States, uncertainty in projecting sea level rise is mainly associated with uncertainty in atmosphere-ocean processes.
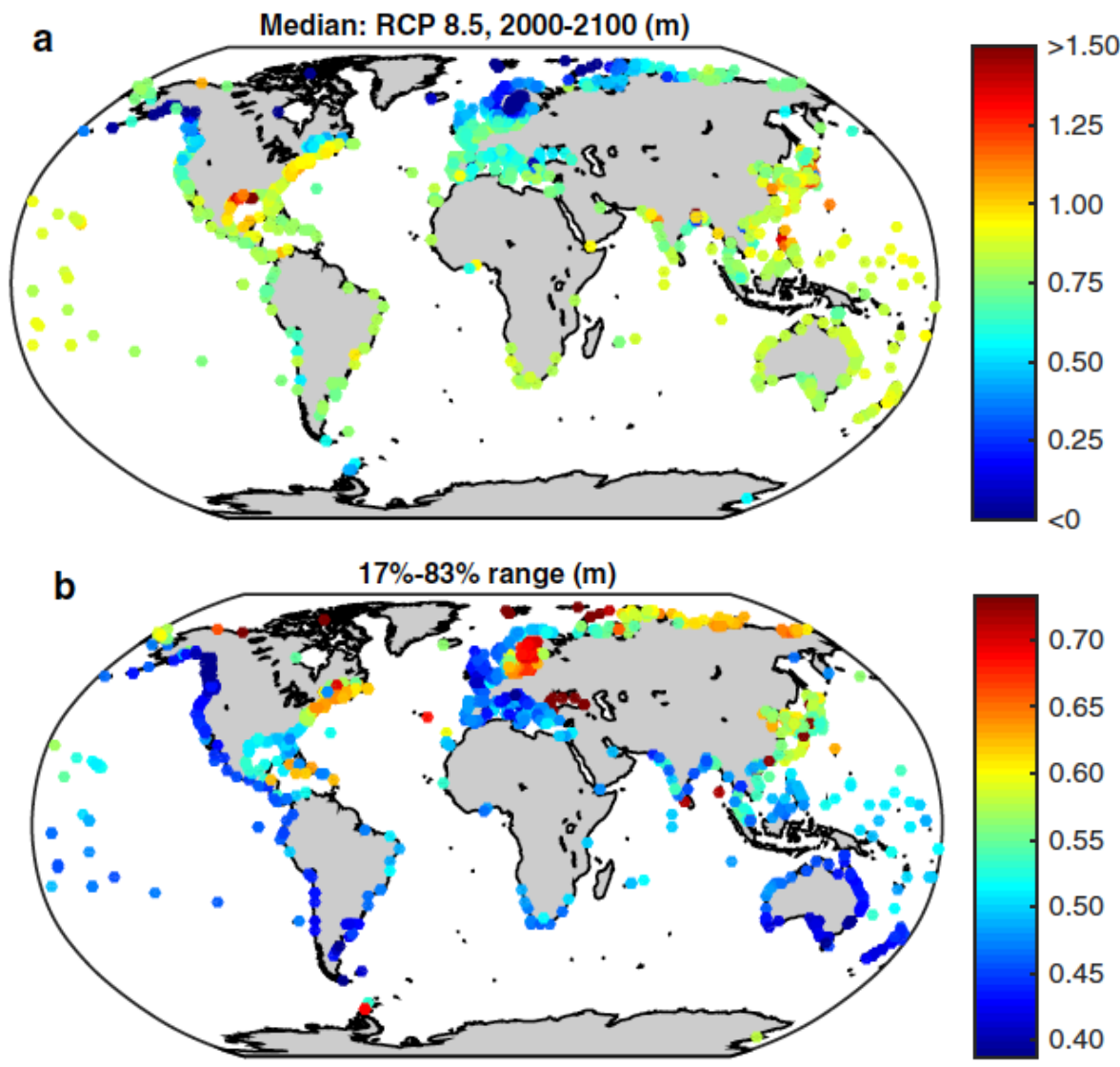

Figure 2.10. Inter-model median (upper) and 17 to 83 percent range (bottom) of sea level rise projected by a multi-model ensemble in meters (Kopp et al. 2014). 
To reduce uncertainty in projecting sea level changes, future research needs to pay more attention to improving understanding of some key processes such as ice sheet dynamics and their interactions. While ocean models driven by observed atmospheric states can reasonably reproduce the dynamic sea level changes in the past (Griffies et al. 2014), large biases still exist in coupled atmosphere-ocean models, particularly in the equatorial and southern oceans (Landerer et al. 2014). Numerical models of geological driven sea level changes have advanced, but complex three-dimensional models are rarely used in projecting sea level changes in the future. Improvements in projecting sea level changes in the near future may come from modeling of process interactions that have not been incorporated to an extent possible in the past. 


\subsection{Summary of Climate Change Projections for the U.S.}

In 2013, U.S. Department of Energy (DOE) produced a report on "U.S. Energy Sector Vulnerabilities to Climate Change and Extreme Weather." To support national climate change adaptation planning and advance the DOE's goal of promoting energy security, the report examines current and potential future impacts of climate trends in air and water temperatures, regional water availability, and intensity and frequency of storm events, flooding, and sea level rise, which are relevant to the U.S. energy sector. In 2014, the U.S. Global Change Research Program published the Third National Climate Assessment Report that assesses the science of climate change and its impacts across the United States (Melillo et al. 2014). These reports summarize observed climate changes based on a wide range of observational records and projected climate changes for the United States from available regional and global climate model simulations. Here we reproduce summary figures of observed and projected climate changes from these two reports that are relevant for NRC's planning and synthesize the results by regions in a summary table.

\subsection{Temperature}

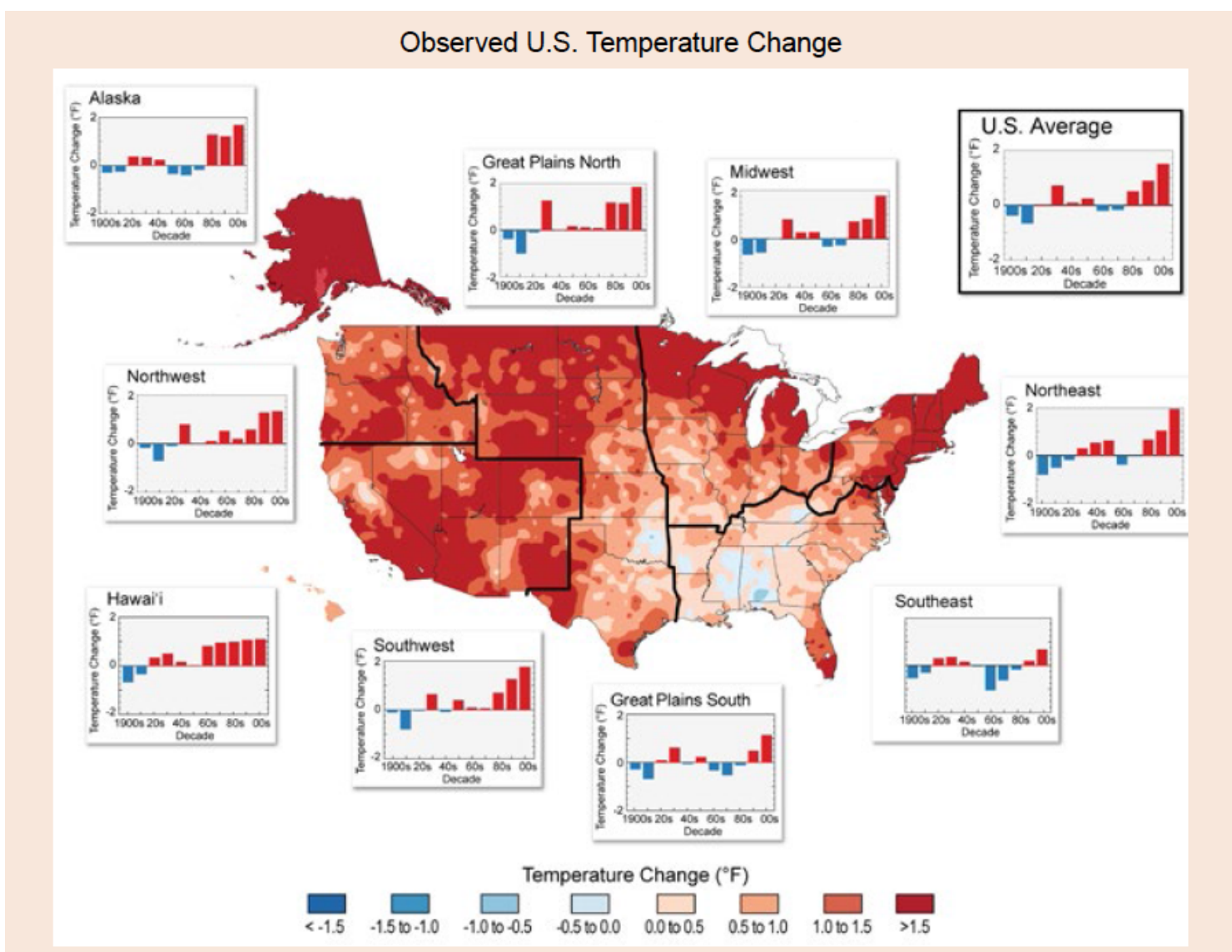

Figure 3.1. Temperature changes over the past 22 years (1991 to 2012) compared to the 1901 to 1960 average, and compared to the 1951 to 1980 average for Alaska and Hawaii. The bars on the graphs show the average temperature changes by decade for 1901 to 2012 (relative to the 1901 to 1960 average) for each region. (Source: Figure 2.7 - Melillo et al. 2014).

\footnotetext{
${ }^{1}$ http://energy.gov/sites/prod/files/2013/07/f2/20130716-Energy\%20Sector\%20Vulnerabilities\%20Report.pdf
} 


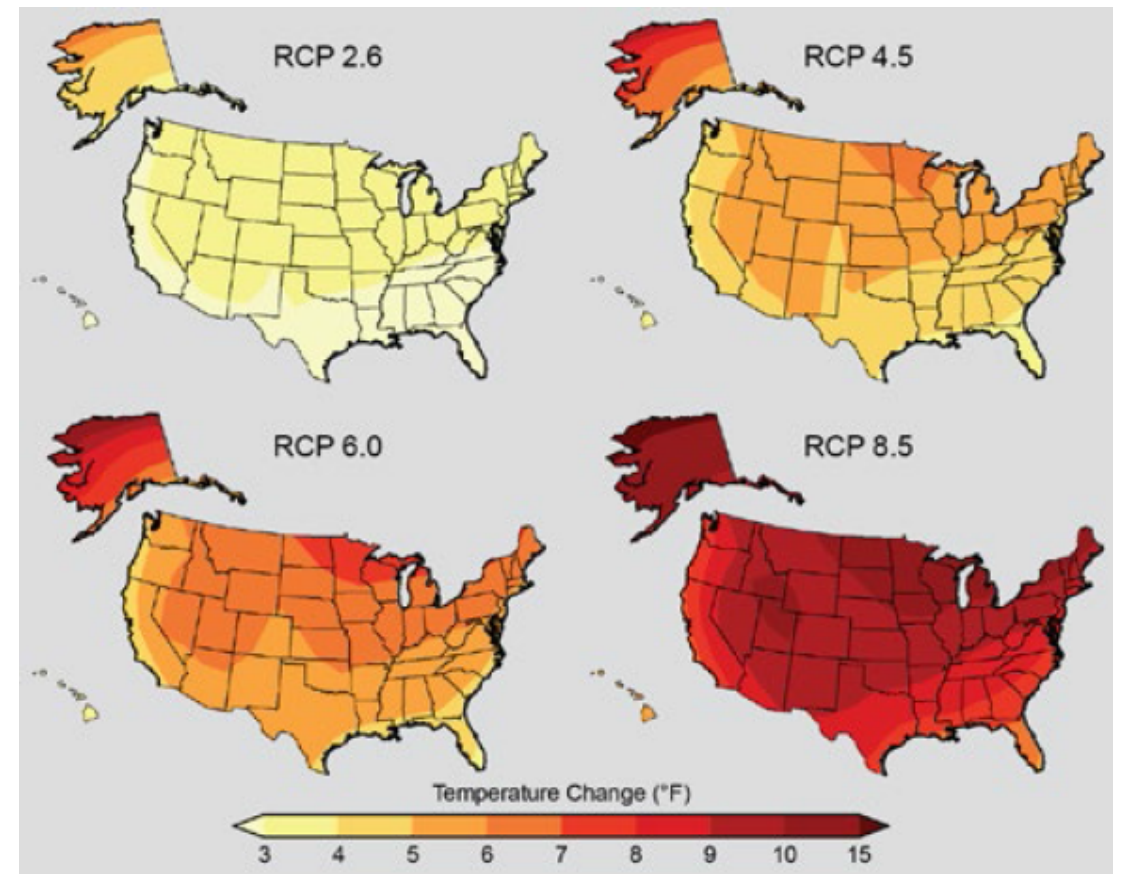

Figure 3.2. Projected changes in surface temperature from CMIP5 models using four emission scenarios corresponding to a climate forcing ranging from $2.6 \mathrm{Wm}^{-2}$ to $8.5 \mathrm{Wm}^{-2}$ by the end of the $21^{\text {st }}$ century. (Source: Figure 2.9 of Melillo et al. 2014).

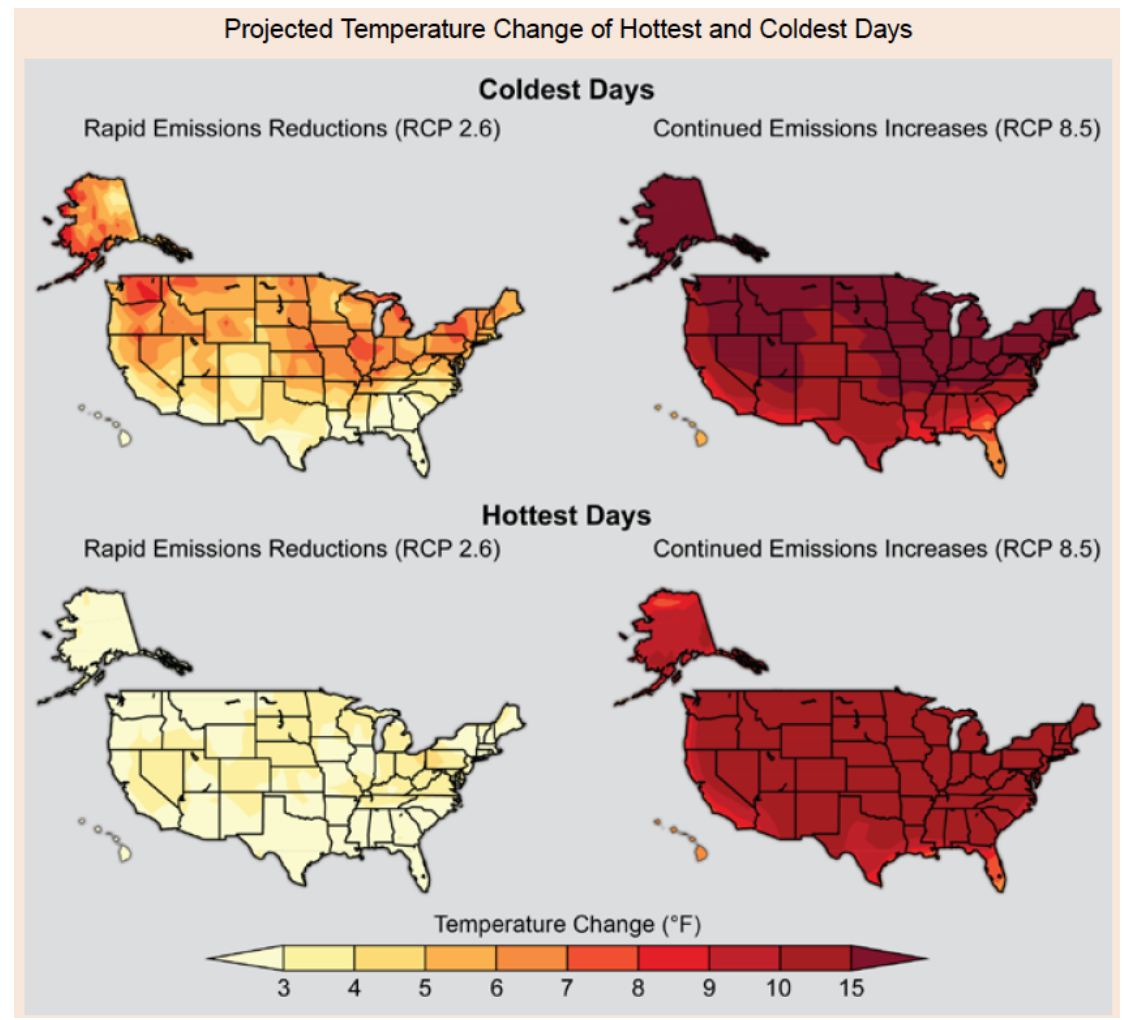

Figure 3.3. Same as Figure 3.2, but for changes in hottest and coldest days. (Source: Figure 2.20 of Melillo et al. 2014) 


\subsection{Precipitation and Floods}

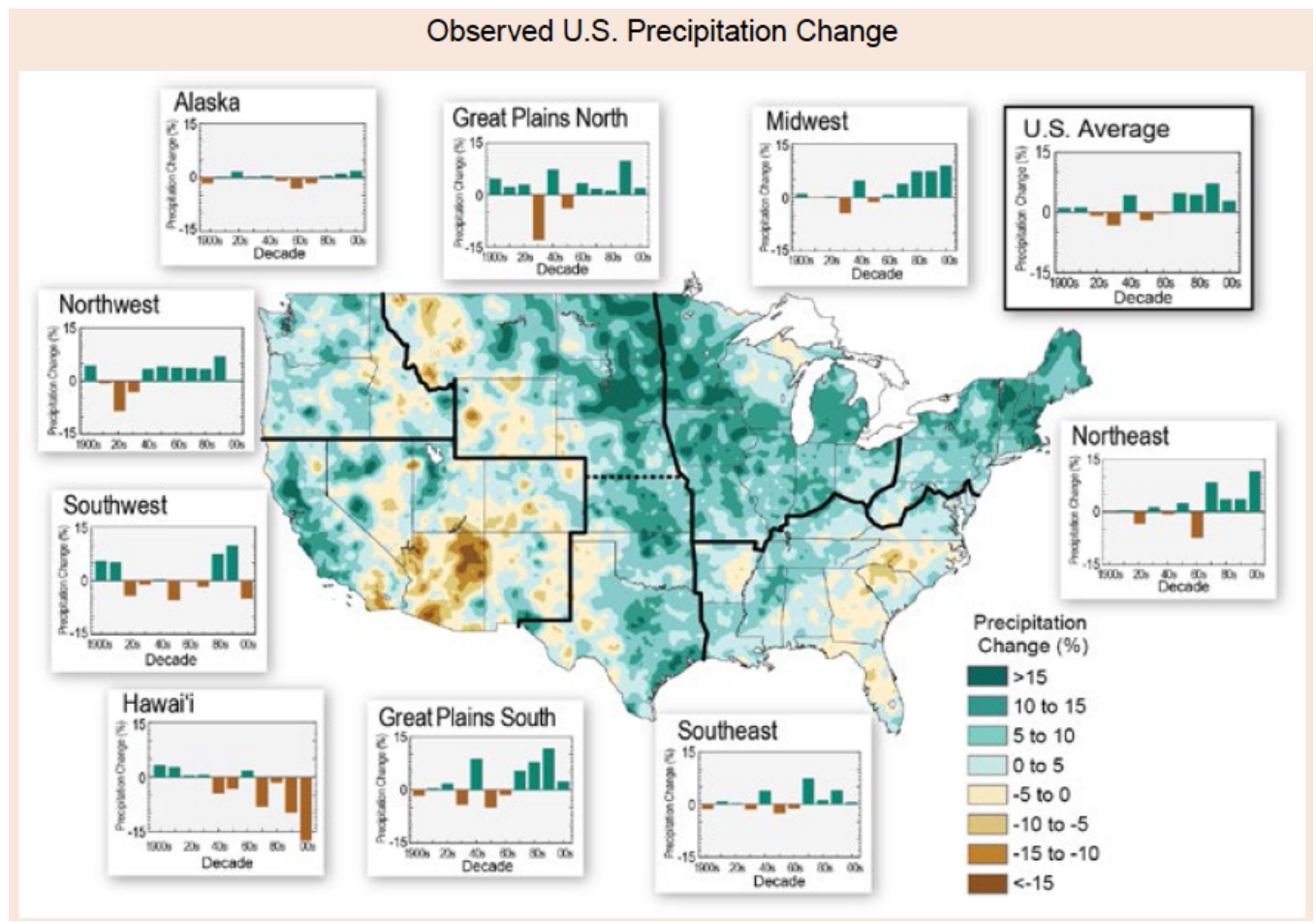

Figure 3.4. Similar to Figure 3.1, but for observed precipitation changes. (Source: Figure 2.12 of Melillo et al. 2014).

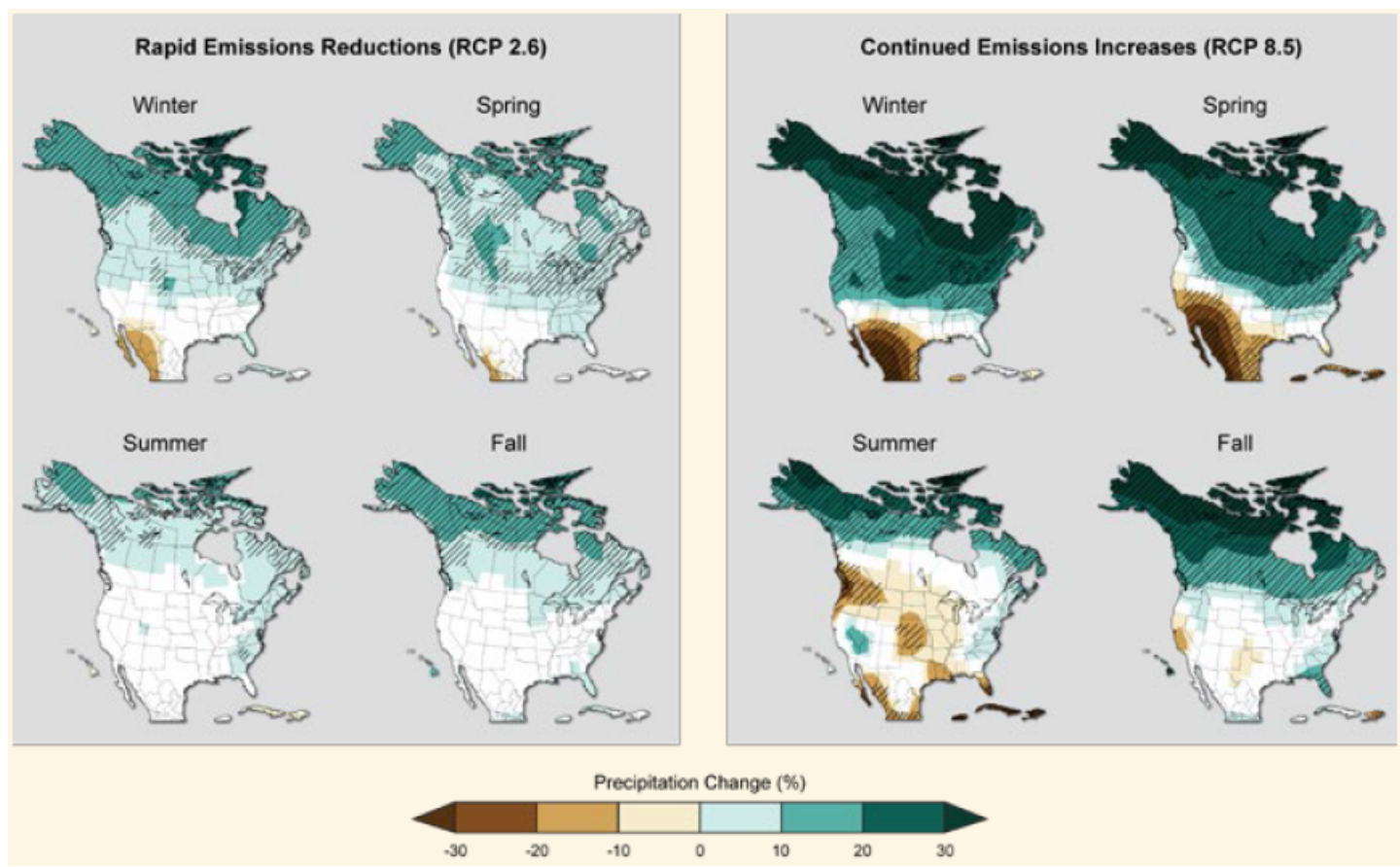

Figure 3.5. Projected changes in mean precipitation for four seasons from CMIP5 models using four emission scenarios corresponding to a climate forcing ranging from $2.6 \mathrm{Wm}^{-2}$ to $8.5 \mathrm{Wm}^{-2}$ by the end of the $21^{\text {st }}$ century. (Source: Figure 2.15 of Melillo et al. 2014). 


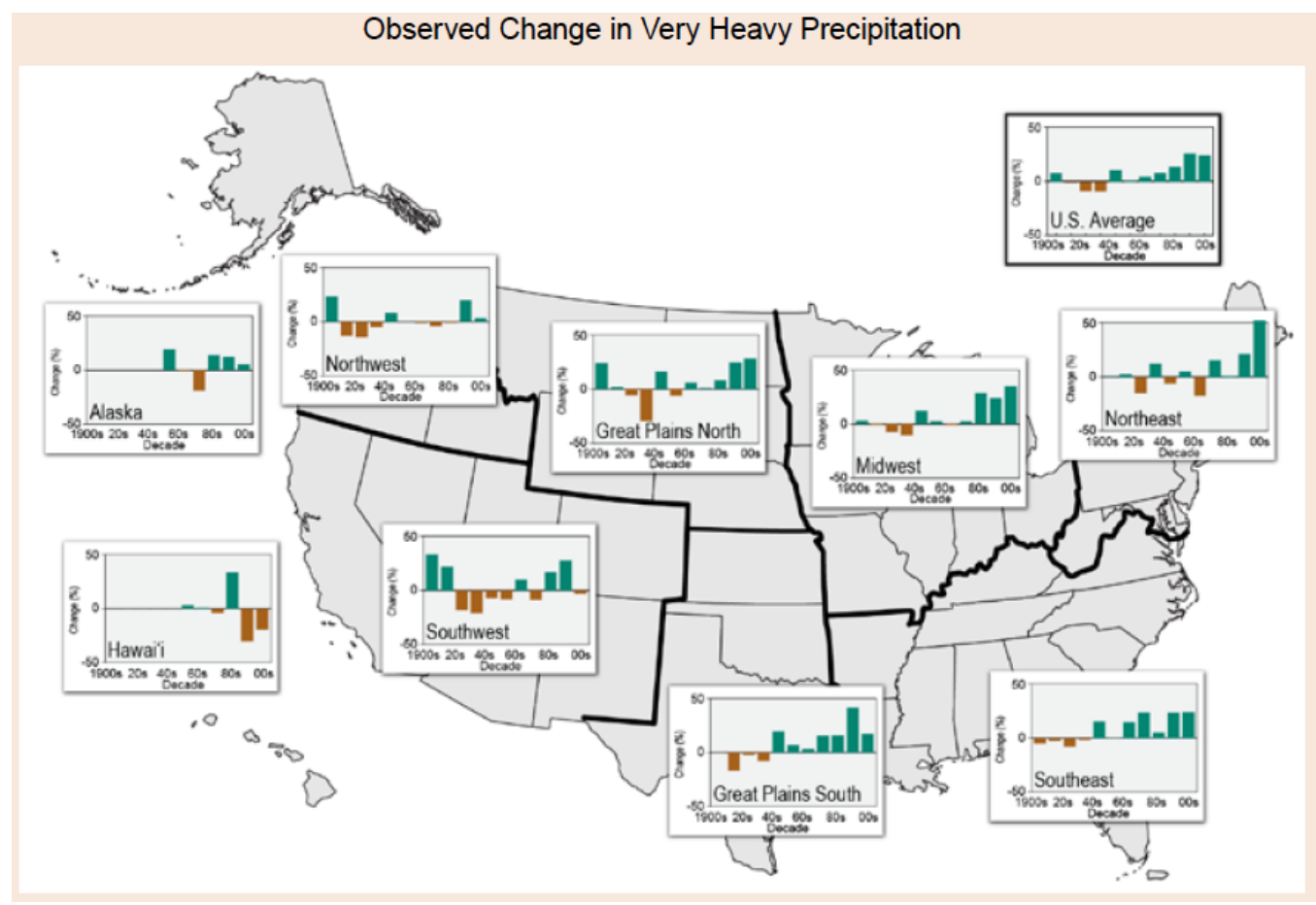

Figure 3.6. Similar to Figure 3.4 but for observed very heavy precipitation changes. Very heavy precipitation is defined as the heaviest 1 percent of all daily events from 1901 to 2012 for each region. (Source: Figure 2.17 of Melillo et al. 2014).

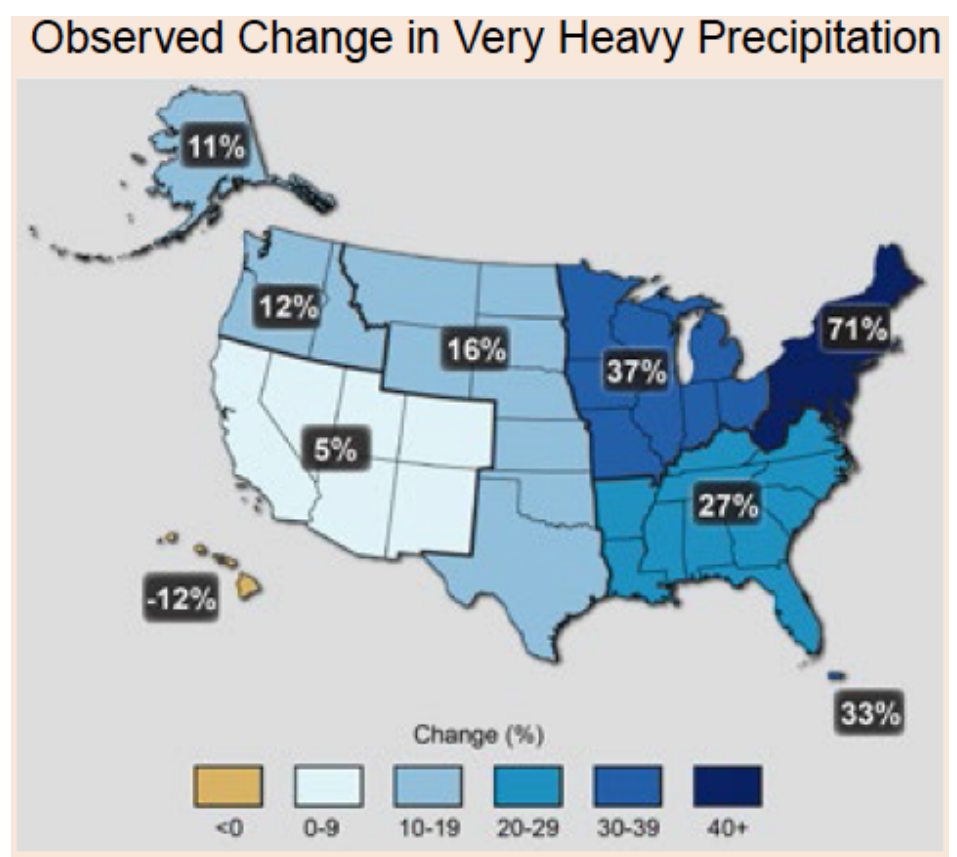

Figure 3.7. Percent increases in the amount of precipitation in very heavy events from 1958 to 2012 for each U.S. region. (Source: Figure 2.18 of Melillo et al. 2014). 


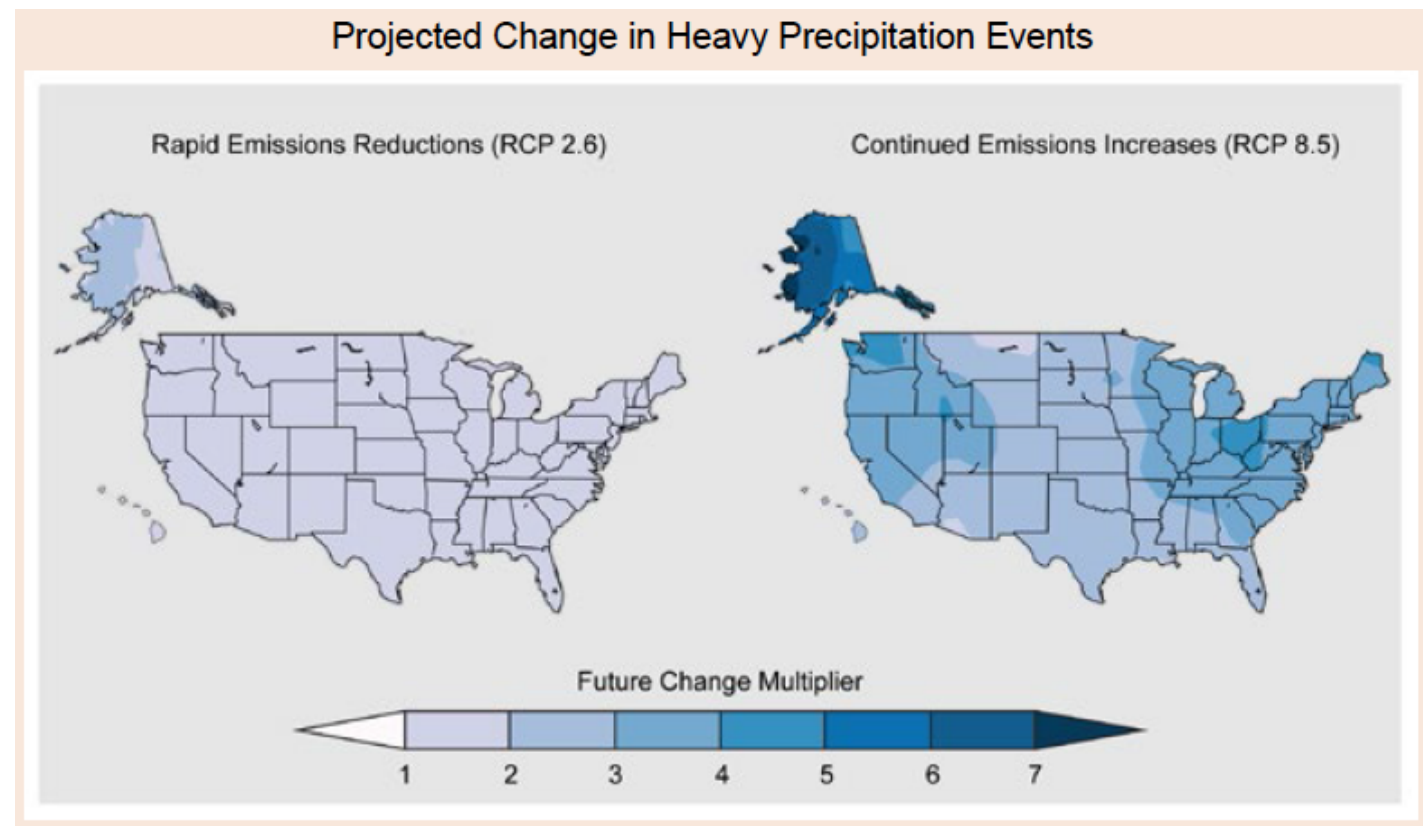

Figure 3.8. Projected changes in the frequency of extreme precipitation events (events that occur once in 20 years in the current climate) in two emission scenarios. (Source: Figure 2.19 of Melillo et al. 2014).

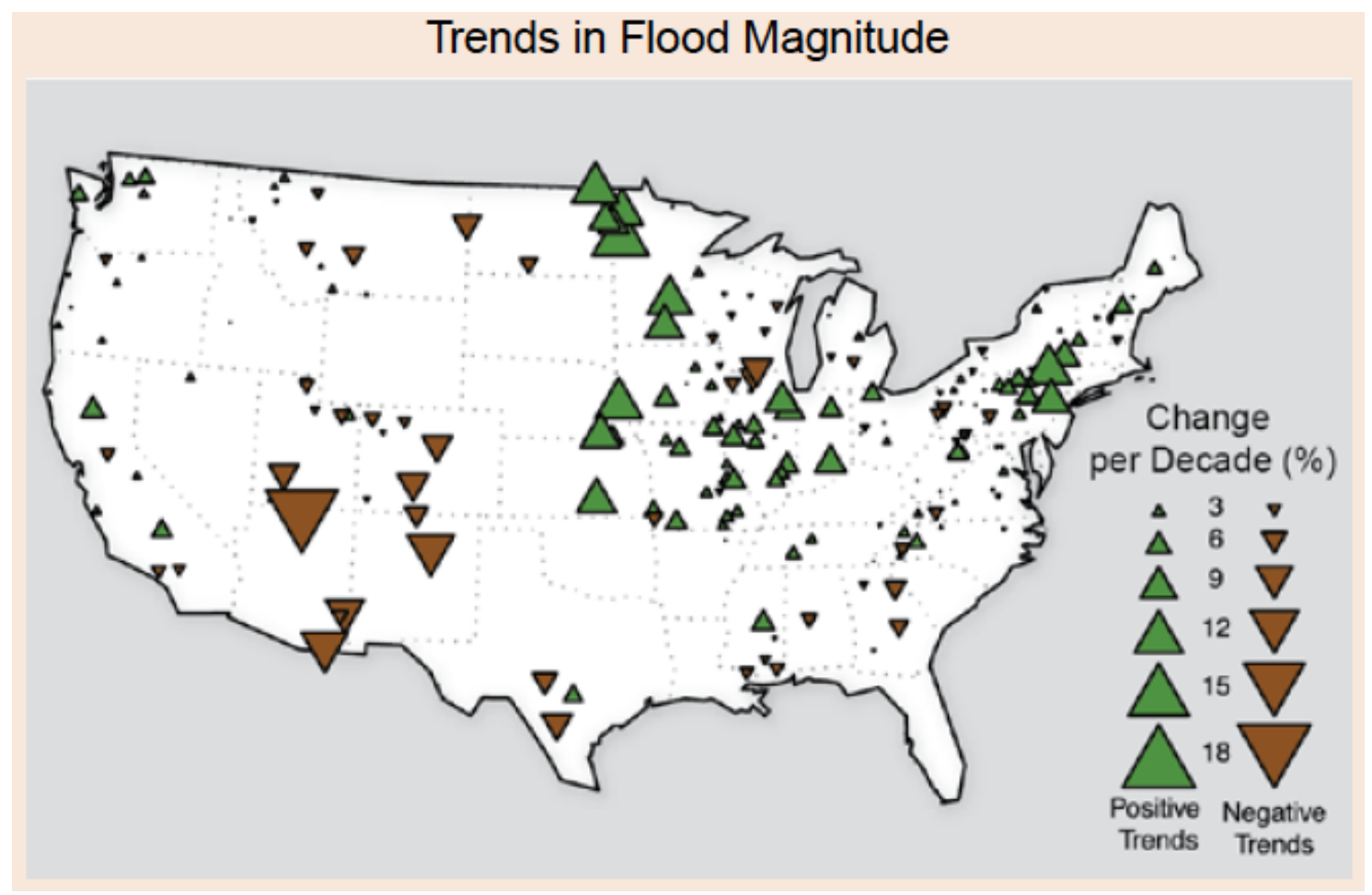

Figure 3.9. Trends of annual flood magnitude from 1920s through 2008. (Source: Figure 2.21 of Melillo et al. 2014). 


\subsection{Hurricanes and Sea Level Rise}

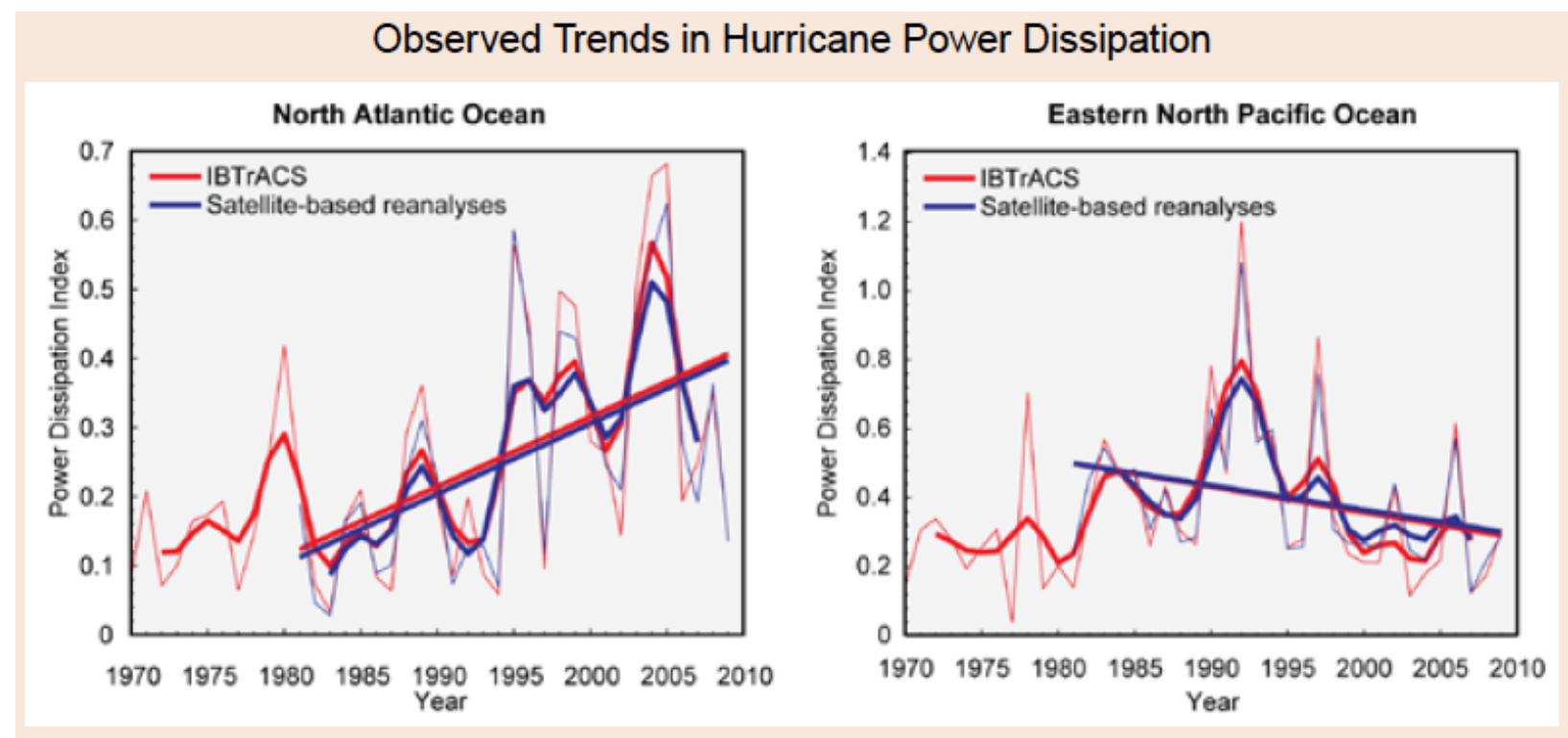

Figure 3.10. Recent variations of the Power Dissipation Index in the North Atlantic and eastern North Pacific Oceans. (Source: Figure 2.23 of Melillo et al. 2014).

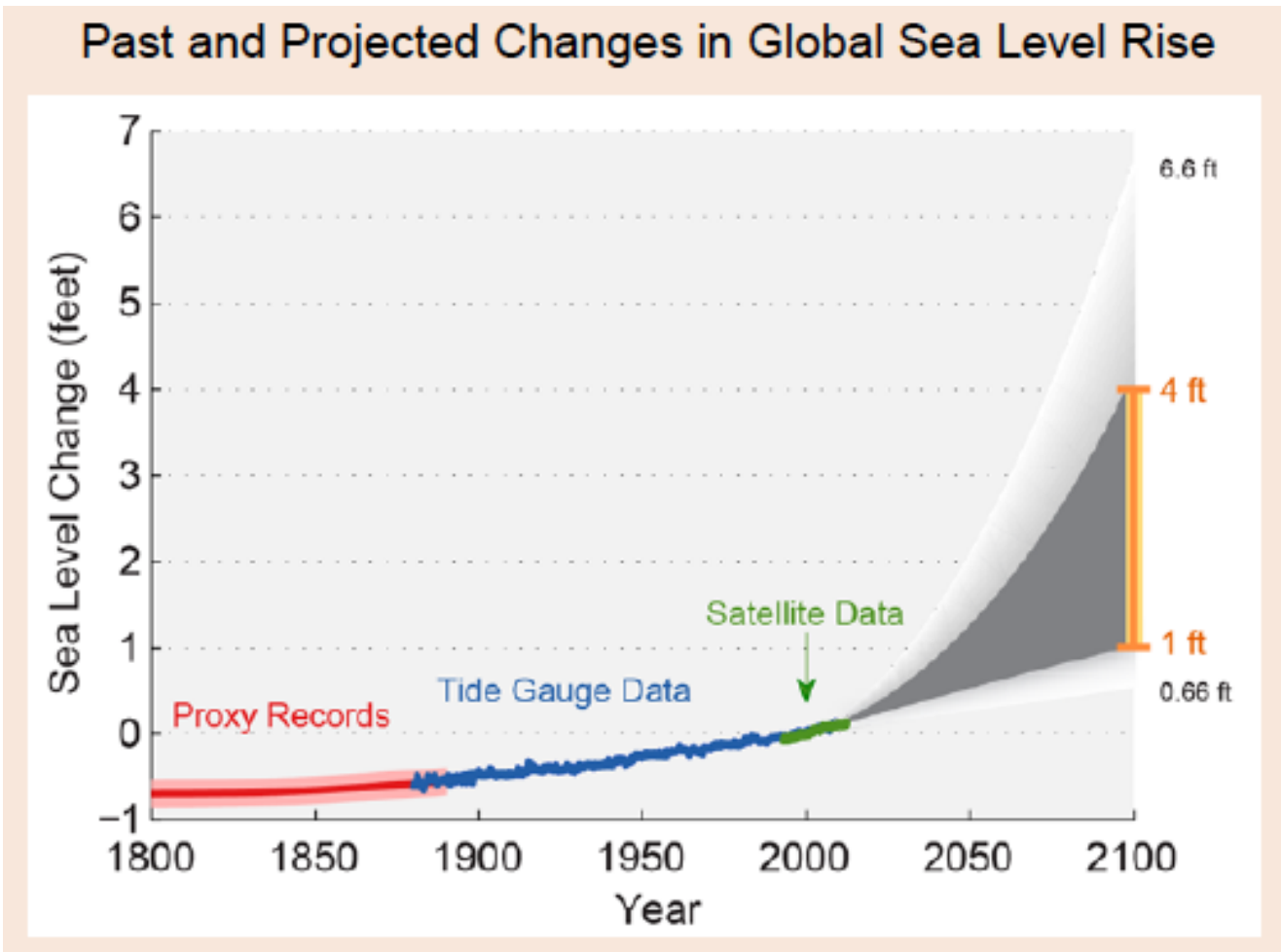

Figure 3.11. Estimated, observed, and possible future amounts of global sea level rise from 1800 to 2100 relative to the year 2000. (Source: Figure 2.26 of Melillo et al. 2014). 


\subsection{Summary of Climate Impacts}

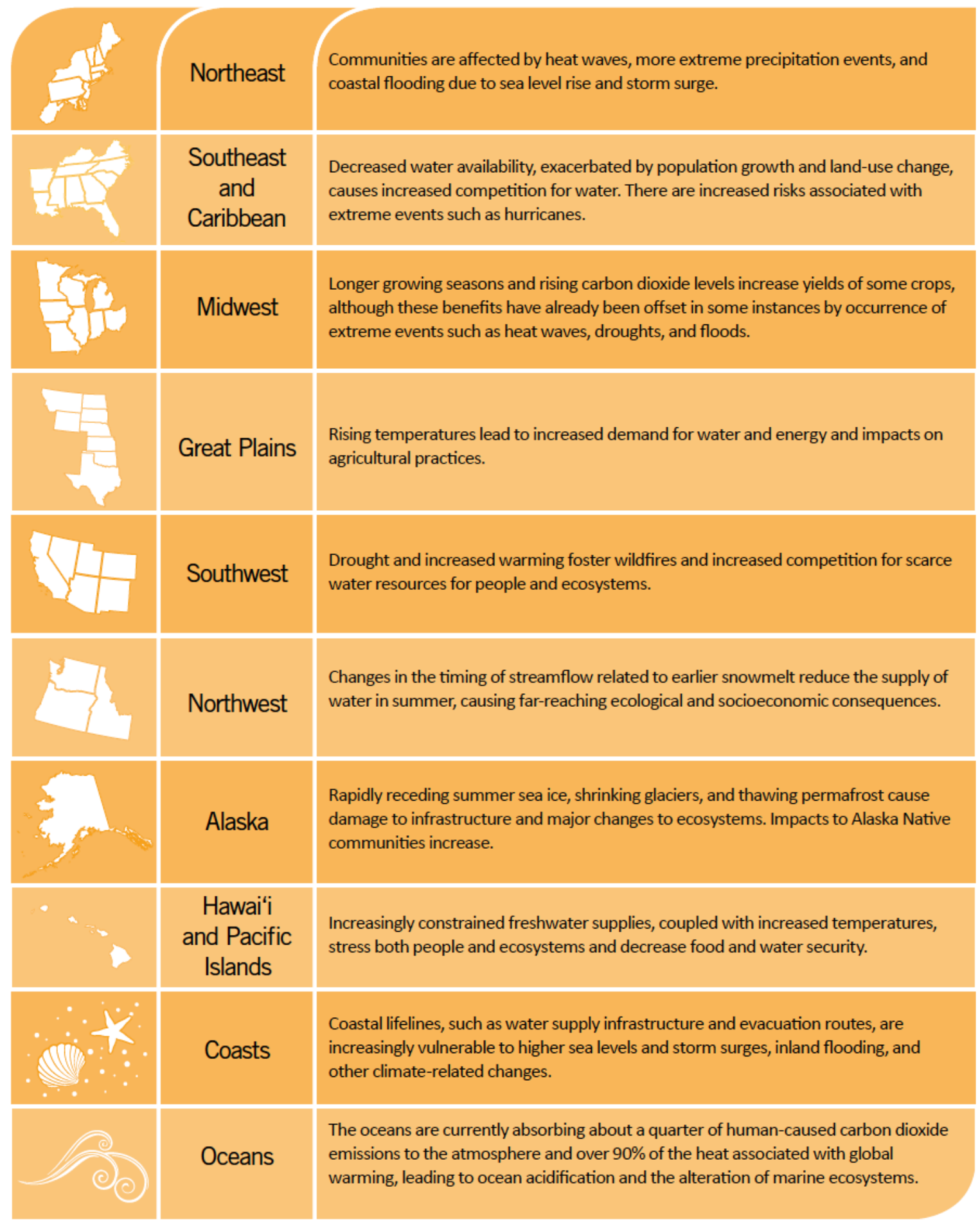

Figure 3.12. Summary of climate impacts by U.S. regions. (Source: Overview in Melillo et al. 2014). 


\subsection{Status in Climate Modeling and Federal Agency Activities}

Climate models are the primary tools for projecting climate change because they encapsulate the complex processes that govern the forcing and response of the Earth systems to human perturbations. Advances in improving model representations of Earth system processes and missing processes and increasing model resolution enabled by high-performance computing have improved model skill in simulating climate over the past decades (National Research Council 2012). Most climate modeling centers participate in the CMIP that generates multi-model ensembles of present and future climate used in the IPCC. The most recent results (i.e., CMIP5) were used in the IPCC Fifth Assessment Report (Stocker et al. 2013). A collection of papers on climate changes in North America from CMIP5 was published in a Journal of Climate special issue (Vol 26, December 2013). The multi-model ensemble framework of CMIP5 has enabled more advanced assessment of uncertainty in projecting future changes and evaluation of model skill. The North American Regional Climate Change Assessment Program (NARCCAP) (Mearns et al. 2012; 2013) represents another multi-model framework that uses multiple regional climate models to dynamically downscale multiple global climate simulations of current and future climate. NARCCAP results have been used prominently in the U.S. National Assessment of Climate Change and facilitated numerous studies of regional climate change and assessment of climate change impacts on water resources, wind energy, agriculture, extreme events, etc. (Mearns et al. 2015). Besides multi-model ensemble, Kay et al. (2015) developed a large ensemble (32 members) of climate simulations using a single global climate model to enable better quantification of internal variability and evaluate the robustness of regional climate change signals in the presence of noise. The climate modeling community has begun to plan and coordinate modeling experiments and simulations for the next phase of CMIP6 (Meehl et al. 2014).

In addition to improvements in climate model fidelity and development of multi-model ensemble and single-model large ensemble of climate change simulations to quantify uncertainty of climate change, the use of modeling hierarchy has advanced understanding and theory of climate change. In hierarchical modeling (e.g., Leung et al. 2013), simulations from idealized configurations (e.g., aquaplanet) to realistic configuration from single component (e.g., atmosphere-only) to the coupled system of the real world are performed to facilitate analysis and interpretations of the model response to global warming (e.g., O'Gorman and Schneider 2009). Modeling experiments have further revealed the potential for key climatic features (e.g., the jet stream) to converge as models reach a horizontal resolution of $\sim 50 \mathrm{~km}$ (e.g., Demory et al. 2014; Lu et al. 2015). If these findings are confirmed by multiple models, a potential implication is that models at $\sim 50 \mathrm{~km}$ resolution may be able to more robustly project climate changes in the future as model sensitivity to resolution is a major source of uncertainty in climate modeling.

A report on "A National Strategy for Advancing Climate Modeling” (National Research Council 2012) recommended a strategy that includes (1) evolution towards a common national software infrastructure to support a diverse hierarchy of different models aimed at improving the performance of climate models on extreme scale computing architectures; (2) convening an annual climate modeling forum that promotes tighter coordination among climate modeling centers; (3) nurturing a unified weather-climate modeling effort to better exploit the synergies between weather forecasting, data assimilation, and climate modeling; and (4) developing training, accreditation, and continuing education for "climate interpreters" who will act as a two-way interface between modeling advances and diverse user needs. Since 2012, some progress has been made to realize the strategy recommended by the report. For example, the National Oceanic and Atmospheric Administration (NOAA) recently began funding a major model development effort to develop the Next Generation Global Prediction System that will adopt a unified weather-climate modeling framework. The first U.S. Climate Modeling Summit was held in February 2015. This summit brought together six premier U.S. climate modeling centers (NOAA Geophysical Fluid Dynamics Laboratory, NOAA National Centers for Environmental Prediction, National Aeronautics 
and Space Administration [NASA] Goddard Institute for Space Studies, NASA Global Modeling and Assimilation Office, Community Earth System Model, and DOE Accelerated Climate Modeling for Energy) to strategize priorities of national interest and coordinate research activities. There are ongoing efforts among different agencies to advance high-performance computing and discussion of model interoperability that may support a common software infrastructure for diverse modeling frameworks. However, it remains unclear whether or how the U.S. government may support a national climate service to better support the climate change information needs of diverse users of climate information (e.g., for planning and management of resources).

Changes in extreme events are high priority climate change information for NRC's safety and environment reviews (Table 1.1). Research in extreme event attribution has advanced rapidly over the last decade to understand and quantify the extent to which climate change influences the magnitude or probability of occurrence of an individual extreme weather or climate event. A report on "Attribution of Extreme Weather Events in the Context of Climate Change" explores the framing and attribution methods used in extreme event attribution (National Academies of Sciences, Engineering, and Medicine 2016). The report also provides a synopsis of attribution of nine specific types of extreme events (extreme heat events, extreme cold events, droughts, wildfires, extreme rainfall, extratropical cyclones, extreme snow and ice storms, tropical cyclones, and severe convective storms). Two classes of event attribution approaches that (1) determine the change in magnitude or probability of events based on observational record and (2) make use of climate simulations to compare how an event would manifest in a world with and without human-caused climate change were broadly discussed. The report noted that event attribution that is based on "sound physical principles, consistent evidence from observations, and numerical models that can replicate the event" are more reliable. However, non-meteorological factors such as wildfires can limit the accuracy of model simulations of extreme events.

Based on the above criteria, the report concluded that confidence in attributing extreme events that are related to an aspect of temperature (e.g., extreme heat and cold events) is greatest because the anthropogenic influence on regional and global warming trends has already been well established. There is also confidence in attributing hydrological drought and heavy precipitation, but attribution of severe convective storms and extratropical cyclones has little or no confidence. Further, one cannot answer whether climate change caused a particular event in a deterministic sense because natural variability also influences extreme events. The report recommended a focused effort to improve understanding of specific aspects of weather and climate extremes to improve the ability to perform extreme event attribution through advances in modeling and understanding, as well as efforts to extend the historical record. 


\subsection{References}

Alexander L, P Uotila, and N Nicholls. 2009. Influence of sea surface temperature variability on global temperature and precipitation extremes. J. Geophys. Res., 114, D18116.

Barnes EA, LM Polvani, and AH Sobel. 2013. Model projections of atmospheric steering of Sandy-like superstorms. PNAS, 110(38), 15211-15215.

Barnes EA, E Dunn-Signuin, G Masato, and T Woollings. 2014. Exploring recent trends in northern hemisphere blocking. Geophys. Res. Lett., 41, 638-644, doi:10.1002/2013GL058745.

Berg P, C Moseley, and JO Haerter. 2013. Strong increase in convective precipitation in response to higher temperatures. Nat Geosci., 6, 181-5.

Brooks HE. 2013. Severe thunderstorms and climate change. Atmos. Res., 123, 129-38. doi:10.1016/j.atmosres.2012.04.002.

Brooks HE, AR Anderson, K Riemann, I Ebbers, and H Flachs. 2007. Climatological aspects of convective parameters from the NCAR/NCEP reanalysis. Atmos. Res., 83, 294-305.

Brown S, J Caesar, and C Ferro. 2008. Global changes in extreme daily temperature since 1950. J. Geophys. Res., 113, D05115, doi:10.1029/2006JD008091.

Camargo SJ. 2013. Global and Regional Aspects of Tropical Cyclone Activity in the CMIP5 Models. $J$. Clim., 26, 9880-9902. doi: 10.1175/JCLI-D-12-00549.1.

Chang EKM, Y Guo, and X Xia. 2012. CMIP5 multimodel ensemble projection of storm track change under global warming. J. Geophys. Res., 117, D23118, doi:10.1029/2012JD018578.

Cohen J, J Screen, JC Furtado, M Barlow, D Whittleston, D Coumou, J Francis, K Dethloff, D Entekhabi, J Overland, J Jones. 2014. Recent Arctic amplification and extreme mid-latitude weather. Nat. Geosci., 7, 627-637, doi:10.1038/ngeo2234.

Cook BI, TR Ault, and JE Smerdon. 2015. Unprecedented 21st century drought risk in the American Southwest and Central Plains. Sci. Adv., 1, e1400082.

Del Genio AD, MS Yao, and J Jonas. 2007. Will moist convection be stronger in a warmer climate? Geophys. Res. Lett., 34, L16,703. doi:10.1029/2007GL030525.

Demory M-E, PL Vidale, MJ Roberts, P Berrisford, J Strachan, R Schiemann, MS Mizielinski. 2014. The role of horizontal resolution in simulating drivers of the global hydrological cycle. Clim. Dyn., 42, 22012225, DOI 10.1007/s00382-013-1924-4.

Dettinger MD. 2011. Climate change, atmospheric rivers, and floods in California - A multimodel analysis of storm frequency and magnitude changes. JAWRA J. Amer. Water Resour. Assoc., 47(3), 514523.

Dettinger MD. 2013. Atmospheric rivers as drought busters on the U.S. west coast. J. Hydrometeor., 14(6), 1721-1732. 
Diffenbaugh NS and M Ashfaq. 2010. Intensification of hot extremes in the United States. Geophys. Res. Lett., 37(15), DOI: 10.1029/2010GL043888.

Diffenbaugh NS, M Scherer, RJ Trapp. 2013. Robust increases in severe thunderstorm environments in response to greenhouse forcing. Proc. Natl. Acad. Sci. (USA), 101, 16,361-6.

doi:10.1073/pnas.1307758110.

Elsner JB, JP Kossin, and TH Jagger. 2008. The increasing intensity of the strongest tropical cyclones. Nature, 455, no. 7209, 92-95.

Francis JA and SJ Vavrus. 2012. Evidence linking Arctic amplification to extreme weather in midlatitudes. Geophys. Res. Lett., 39, L06801, doi:10.1029/2012GL051000.

Gao Y, LR Leung, EP Salathé, F Dominguez, B Njissen, and DP Lettenmaier. 2012. Moisture flux convergence in regional and global climate models: Implications for droughts in the southwestern United States. Geophys. Res. Lett., doi:10.1029/2012GL051560.

Gao Y, LR Leung, J Lu, Y Liu, M Huang, and Y Qian. 2014. Robust spring drying in the southwestern U.S. and seasonal migration of wet/dry patterns in a warmer climate. Geophys. Res. Lett., 41(5), 17451751, doi:10.1002/2014GL059562.

Gao Y, LR Leung, J Lu, and G Masato. 2015a. Persistent cold air outbreaks over North America in a warming climate. Environ. Res. Lett., 10, doi:10.1088/1748-9326/10/4/044001.

Gao Y, J Lu, LR Leung, Q Yang, S Hagos, and Y Qian. 2015b. Dynamical and thermodynamical modulations on future changes of landfalling atmospheric rivers over western North America. Geophys. Res. Lett., 42, 7179-7186, doi:10.1002/2015GL065435.

Gensini VA and TL Mote. 2014. Estimations of hazardous convective weather in the United States using dynamical downscaling. J. Clim., 27, 6581-9.

Griffies SM, J Yin, PJ Durack, P Goddard, SC Bates, E Behrens, M Bentsen, D Bi, W Biastoch, CW Böning, A Bozec, E Chassignet, Gokhan Danabasoglu, Sergey Danilov, Catia M. Domingues, Helge Drange, R Farneti, E Fernandez, RJ Greatbatch, DM Holland, M Ilicak, WG Large, K Lorbacher, J Lu, SJ Marsland, A Mishra, AJG Nurser, D Salas y Mélia, JB Palter, BL Samuels, J Schröter, FU Schwarzkopf, D Sidorenko, AM Treguier, Y Tseng, H Tsujino, P Uotila, S Valcke, A Voldoire, Q Wang, M Winton, X Zhang. 2014. An assessment of global and regional sea level for years 1993-2007 in a suite of interannual CORE-II simulations. Ocean Model, 78, 35-89. doi:10.1016/j.ocemod.2014.03.004.

Grotjahn R, R Black, LR Leung, MF Wehner, M Barlow, M Bosilovich, S Gershunov, W Gutowski, JR Gyakum, RW Katz, Y-Y Lee, Y-K Lim, and M Prabhat. 2016. North American extreme temperature events and related large scale meteorological patterns: A review of statistical methods, dynamics, modeling, and trends. Clim. Dyn., 46(3), 1151-1184, doi: 10.1007/s00382-015-2638-6.

Held IM and BJ Soden. 2006. Robust responses of the hydrological cycle to global warming. J. Clim., 19, 5686-5699.

Hoerling M and A Kumar. 2003. The perfect ocean for drought. Science, 299, 691-694.

Kay JE, C Deser, A Phillips, A Mai, C Hannay, G Strand, JM Arblaster, SC Bates, G Danabasoglu, J Edwards, M Holland, P Kushner, JF Lamarque, D Lawrence, K Lindsay, A Middleton, E Munoz, R 
Mearns LO, DP Lettenmaier, and S McGinnis. 2015. Uses of results of regional climate model experiments for impacts and adaptation studies: the examples of NARCCAP. Curr. Clim. Change Rep., 1, $1-9$.

National Academies of Sciences, Engineering, and Medicine. 2016. Attribution of Extreme Weather Events in the Context of Climate Change. Washington, DC: The National Academies Press. doi: $10.17226 / 21852$.

National Research Council, 2012. A National Strategy for Advancing Climate Modeling. The National Academies Press, ISBN 978-0-309-25977-4, 300 pp.

Neale, K Oleson, L Polvani, and M Vertenstein. 2015. The Community Earth System Model (CESM) Large Ensemble Project: A community resource for studying climate change in the presence of climate variability. Bull. Am. Meteorol. Soc., 96, doi:10.1175/BAMS-D-13-00255.1.

Kendon EJ, NM Roberts, HJ Fowler, MJ Roberts, SC Chan, and CA Senior. 2014. Heavier summer downpours with climate change revealed by weather forecast resolution model. Nat. Clim. Chang., 4 , $570-6$.

Kharin VV and FW Zwiers. 2000. Changes in the extremes in an ensemble of transient climate simulations with a coupled atmosphere-ocean GCM. J. Clim. 13, 3760-3788.

Klein SA, X Jiang, J Boyle, S Malyshev, and S Xie. 2006. Diagnosis of the summertime warm and dry bias over the U.S. southern Great Plains in the GFDL climate model using a weather forecasting approach. Geophys. Res. Lett., 33, L18805, doi:10.1029/2006GL027567.

Knutson TR, JL McBride, J Chan, K Emanuel, G Holland, C Landsea, I Held, JP Kossin, AK Srivastava, and M Sugi. 2010. Tropical cyclones and climate change. Nature Geoscience, 3, no. 3, 157-163.

Knutson TR, JJ Sirutis, GA Vecchi, S Garner, M Zhao, HS Kim, M Bender, RE Tuleya, IM Held, G Villarini. 2013: Dynamical downscaling projections of twenty-first-century Atlantic hurricane activity: CMIP3 and CMIP5 model-based scenarios. J. Climate, 26, 6591-6617.

Kopp RE, RM Horton, CM Little, JX Mitrovica, M Oppenheimer, DJ Rasmussen. 2014. Probabilistic 21 st and 22nd century sea-level projections at a global network of tide gauge sites. Earth Future, 2, 383406. doi:10.1002/2014EF000239.

Kossin JP, KA Emanuel, and GA Vecchi. 2014. The poleward migration of the location of tropical cyclone maximum intensity. Nature, 509, 350-352, doi: 10.1038/nature13278.

Landerer FW, PJ Gleckler, T Lee. 2014. Evaluation of CMIP5 dynamic sea surface height multi-model simulations against satellite observations. Clim Dyn., 43, 1271-83. doi:10.1007/s00382-013-1939-x.

Lau NC and MJ Nath. 2012. A model study of heat waves over North America: Meteorological aspects and projections for the Twenty-First Century. J. Clim., 25, 4761-4784. doi: 10.1175/JCLI-D-11-00575.1.

Lenderink $\mathrm{G}$ and $\mathrm{E}$ van Meijgaard. 2008. Increases in hourly precipitation extremes beyond expectations from temperature changes. Nat. Geosci., 1, 511-514.

Lepore C, D Veneziano, and A Molini. 2014. Temperature and CAPE dependence of rainfall extremes in the eastern United States. Geophys. Res. Lett., 42, doi:10.1002/2014GL062247. 
Leung LR and Y Qian. 2009. Atmospheric rivers induced heavy precipitation and flooding in the western U.S. simulated by the WRF regional climate model. Geophys. Res. Lett, 36(3), L03820.

Leung LR, T Ringler, WD Collins, M Taylor, and M Ashfaq. 2013. A hierarchical evaluation of regional climate simulations. Eos Transactions, 297-298, doi: 10.1002/2013EO340001.

Li W, L Li, M Ting, and Y Liu. 2012. Intensification of northern hemisphere subtropical highs in a warming climate. Nat. Geosci., 5, 830-834, doi: 10.1038/NGEO1590.

Lin N, K Emanuel, M Oppenheimer, and E Vanmarcke. 2012. Physically based assessment of hurricane surge threat under climate change. Nature Clim. Change, 2, 462-467.

Lu J, GA Vecchi, and T Reichler. 2007. Expansion of the Hadley cell under global warming. Geophys. Res. Lett., 34, L06805, doi:10.1029/2006GL028443.

Lu J, LR Leung, Q Yang, G Chen, WD Collins, F Li, Z Hou, and X Feng. 2014. The robust dynamical contribution to precipitation extremes in idealized warming simulations across model resolutions. Geophys. Res. Lett., 41, 2971-2978, doi: 10.1002/2014GL059532.

Lu J, G Chen, LR Leung, A Burrows, Q Yang, K Sakaguchi, and S Hagos. 2015. Towards the dynamical convergence on the jet stream in aquaplanet AGCMs. J. Clim., 28, 6763-6782, doi: 10.1175/JCLI-D-1400761.1.

Mearns LO, R Arritt, S Biner, M Bukovsky, S Sain, D Caya, D Flory, W Gutowski, R Jones, W Moufouma-Okia, R Leung, Y Qian, J Correia, Jr, S McGinnis, L McDaniel, A Nunes, J Roads, L Sloan, M Synder, G Takle, R Laprise. 2012. The North American Regional Climate Change Assessment Program: Overview of phase I results. Bull. Amer. Meteorol. Soc., 93(9), doi:10.1175/BAMS-D-1100223.1.

Mearns LO, S Sain, LR Leung, MS Bukovsky, S McGinnis, S Biner, D Caya, RW Arritt, W Gutowski, E Takle, M Synder, RG Jones, AMB Nunes, S Tucker, D Herzmann, L McDaniel, and L Sloan. 2013. Climate change projections of the North American Regional Climate Change Assessment Program (NARCCAP). Clim. Change Lett., 120(4), 965-975, doi: 10.1007/s10584-013-0831-3.

Meehl GA, R Moss, KE Taylor, V Eyring, RJ Stouffer, S Bony, and B Stevens. 2014. Climate model intercomparisons: Preparing for the next phase. EOS Transactions, 95, 77-78.

Melillo JM, TC Richmond, and GW Yohe, eds. 2014. Climate Change Impacts in the United States: The Third National Climate Assessment. U.S. Global Change Research Program, 841 pp. doi:10.7930/J0Z31WJ2.

National Research Council. 2012. A National Strategy for Advancing Climate Modeling. The National Academies Press, ISBN 978-0-309-25977-4, 300 pp.

Neiman PJ, LJ Schick, FM Ralph, M Hughes, and GA Wick. 2011. Flooding in western washington: the connection to atmospheric rivers. J. Hydrometeor., 12(6), 1337-1358.

Nicholls RJ and A Cazenave. 2010. Sea-level rise and its impacts on coastal zones. Science, 328, 15171520 . 
O'Gorman PA and T Schneider. 2009. Scaling of precipitation extremes over a wide range of climates simulated with an idealized GCM. J. Clim., 22, 5676-5685.

O'Gorman PA. 2014. Contrasting responses of mean and extreme snowfall to climate change. Nature, $512,416-418$.

O’Gorman PA. 2015. Precipitation extremes under climate change. Curr. Clim. Change Rep., 1, 49-59.

Peterson TC, R Heim, R Hirsch, D Kaiser, H Brooks, DS Diffenbaugh, R Dole, J Giovannettone, K Guiguis, TR Karl, RW Katz, K Kunkel, D Lettenmaier, GJ. McCabe, CJ. Paciorek, K Ryberg, S Schubert, Silva VBS, B Stewart, AV Vecchia, G Villarini, RS Vose, J Walsh, M Wehner, D Wolock, K Wolter, CA Woodhouse, and D Wuebbles. 2013. Monitoring and Understanding Changes in Heat waves, Cold waves, Floods and Droughts in the United States: State of Knowledge. Bull. Amer. Meteor. Soc., 94: 821-834, DOI: 10.1175/BAMS-D-12-00066.1, Supplement DOI: 10.1175/BAMS-D-12-00066.2

Ralph FM, PJ Neiman, GA Wick, SI Gutman, MD Dettinger, DR Cayan, and AB White. 2006. Flooding on California's Russian River: role of atmospheric rivers. Geophys. Res. Lett. 33(13), L13801.

Schneider T, PA O'Gorman, and XJ Levine. 2010. Water vapor and the dynamics of climate changes. Rev. Geophys., 48, RG3001, doi:10.1029/2009RG000302.

Schneider T, T Bischoff, and H Plotka. 2015. Physics of changes in synoptic midlatitude temperature variability. J. Clim., 28, 2312-2331, doi: 10.1175/JCLI-D-14-00632.1.

Seager R, M Ting, I Held, Y Kushnir, J Lu, G Vecchi, H-P Huang, N Harnik, A Leetmaa, N-C Lau, C Li, J Velez, N Naik. 2007: Model projections of an imminent transition to a more arid climate in southwestern North America. Science, 316, 1181-1184.

Seager R, N Naik and GA Vecchi. 2010. Thermodynamic and dynamic mechanisms for large-scale changes in the hydrological cycle in response to global warming. J. Clim., 23, 4651-4668, doi:

10.1175/2010JCLI3655.1.

Seeley JT and DM Romps. 2015. The effect of global warming on severe thunderstorms in the United States. J. Clim., doi:10.1175/JCLI-D-14-00382.1.

Sherwood S and Q Fu. 2014. A drier future? Science, 343, 737-739, doi: 10.1126/science.1247620.

Sillmann J, VV Kharin, FW Zwiers, X Zhang, and D Bronaugh. 2013. Climate extremes indices in the CMIP5 multi model ensemble: Part 2. Future climate projections. J. Geophys. Res., 118, 2473-2493.

Sillmann J and M Croci-Maspoli. 2009. Present and future atmospheric blocking and its impact on European mean and extreme climate. Geophys. Res. Lett., 36, L10702.

Stocker TF et al. 2013. Technical Summary. In: Climate Change 2013: The Physical Science Basis. Contribution of Working Group I to the Fifth Assessment Report of the Intergovernmental Panel on Climate Change [Stocker, T.F., D. Qin, G.-K. Plattner, M. Tignor, S.K. Allen, J. Boschung, A. Nauels, Y. Xia, V. Bex and P.M. Midgley (eds.)]. Cambridge University Press, Cambridge, United Kingdom and New York, NY, USA.

Sugiyama M, H Shiogama, and S Emori. 2010. Precipitation extreme changes exceeding moisture content increases in MIROC and IPCC climate models. PNAS, 107(2), 571-575, doi: 10.1073/pnas.0903186107. 
Taylor KE, RJ Stouffer, and GA Meehl. 2012. An overview of CMIP5 and the experiment design. Bull. Amer. Meteor. Soc., 93, 485-498.

Tippett MK. 2014: Changing volatility of U.S. annual tornado reports. Geophys. Res. Lett., 41, 6956-61. doi:10.1002/2014GL061347.

Tippett MK, AH Sobel, and SJ Camargo. 2012. Association of U.S. tornado occurrence with monthly environmental parameters. Geophys. Res. Lett., 39, doi:10.1029/2011GL050368.

Trapp RJ, NS Diffenbaugh, HE Brooks, ME Baldwin, ED Robinson, and JS Pal. 2007. Changes in severe thunderstorm environment frequency during the 21 st century caused by anthropogenically enhanced global radiative forcing. Proc. Natl. Acad. Sci. (USA), 104, 19,719-23.

Trenberth KE, A Dai, RM Rasmussen, and DB Parsons. 2004. The changing character of precipitation. Bull. Amer. Meteor. Soc., 1205-1217, doi: 10.1175/BAMS-84-9-1205.

van Oldenborgh GJ, S Drijfhout, A van Ulden, R Haarsma, A Sterl, C Severijns, W Hazeleger, and H Dijkstra. 2009. Western Europe is warming much faster than expected. Clim. Past, 5, 1-12.

Vavrus SJ, JE Walsh, WL Chapman, and D Portis. 2006. The behavior of extreme cold air outbreaks under greenhouse warming. Internat. J. Climatol., 26, 1133.

Vecchi GA and BJ Soden. 2007. Global warming and the weakening of the tropical circulation. J. Clim., 20, 4316-4340.

Villarini G and GA Vecchi. 2012. Twenty-first-century projections of North Atlantic tropical storms from CMIP5 models. Nat. Climate Change, 2, 604-607.

Warner MD, CF Mass, and EP Salathé. 2015. Changes in winter atmospheric rivers along the North American west coast in CMIP5 climate models. J. Hydrometeor., 16(1), 118-128.

Zhu Y and RE Newell. 1998. A proposed algorithm for moisture fluxes from atmospheric rivers. Mon. Wea. Rev., 126(3), 725-735. 



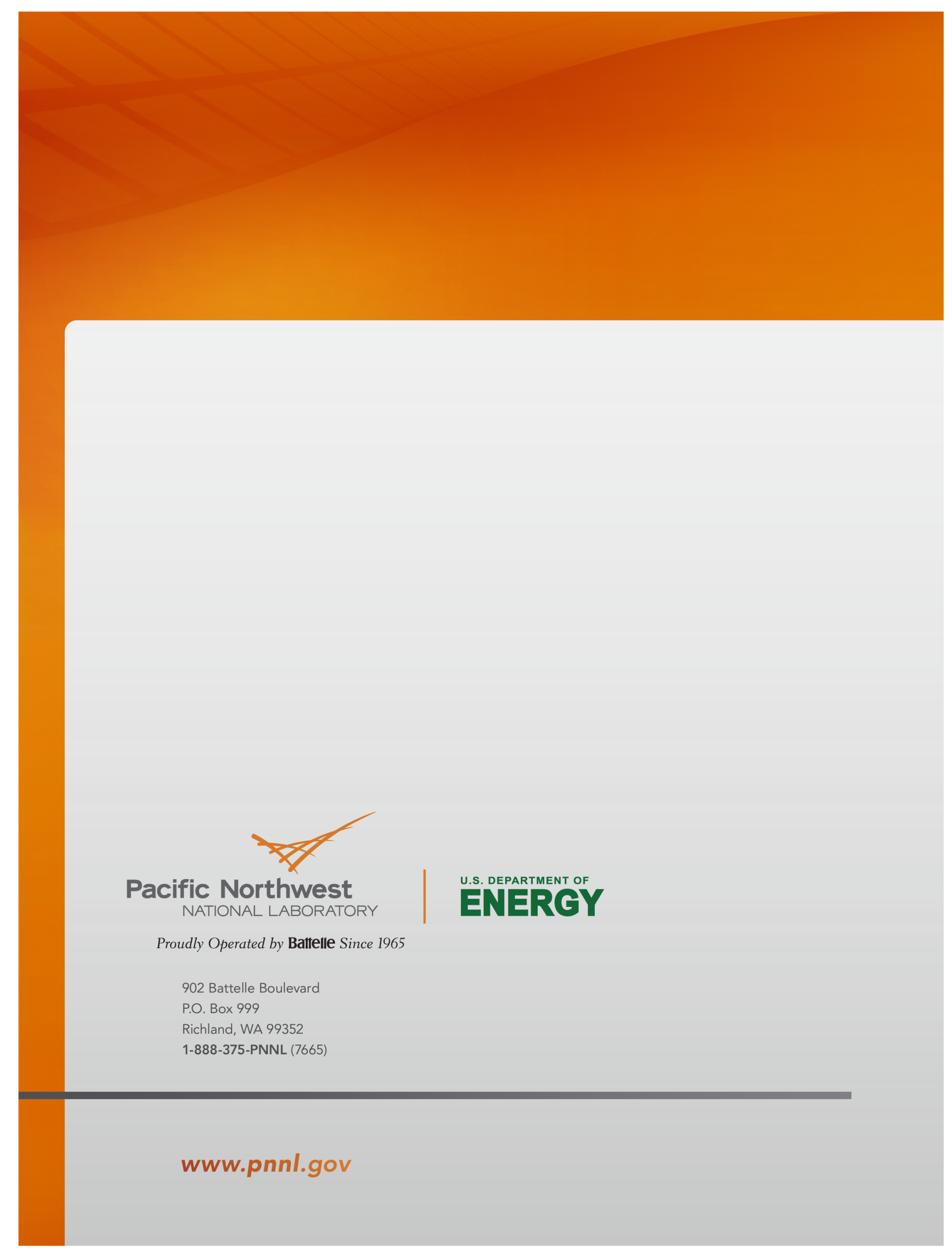

